\title{
Approaches and Mechanisms of Adaptation with Urban, Social and Economic Mobility of Region and Cities of Delta in the light of Global Climate Change Impact
}

\author{
Mohamed Salah El Din Sayed El Sayed; Șalah Mohamed Ibrạhim Kaooud, \\ Moustafa Mounir Mähmoud and Shereen El-Shahaat Okeel
}

\begin{abstract}
:
Global climate change is the biggest challenges that face the future of developmental mobility. Climate change has historic roots known climatic cycles. It increased by greenhouse gases due to increase non-sustainable human activities leading to the presence of serious threats, including rising sea levels and desertification. Adaptation by sustainable development, increasing green areas, practical ecology, management laws and reducing the density. For coastal sectors are subjected to methods of costal engineering, including the building of walls, headers marine and etc, or bridging the lowland or dig seabed. Deltas are facing the most implications of threatened areas, including the Nile Delta, which are subjected to many forces including landing Delta, immersion and drown beaches. Mechanisms and Approaches of coping by maintain farmland, create poles of development of the parties, scalable industrial growth on the coast and within the Delta, which leads to lower density, as well as maintaining developmental systems of lakes.
\end{abstract}

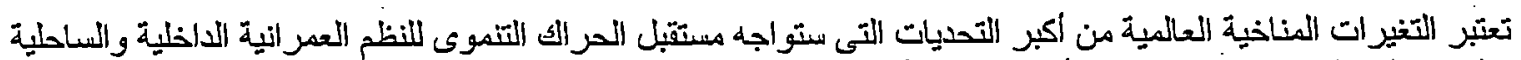

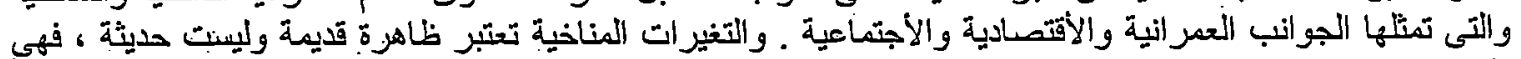

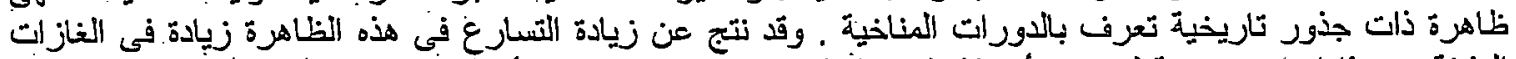

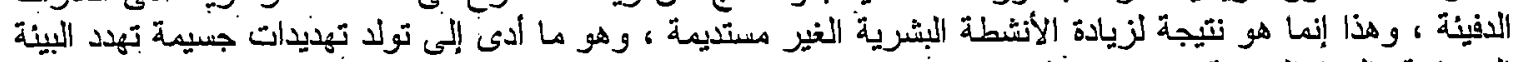

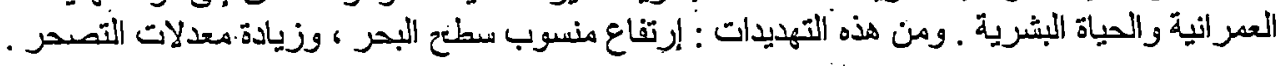

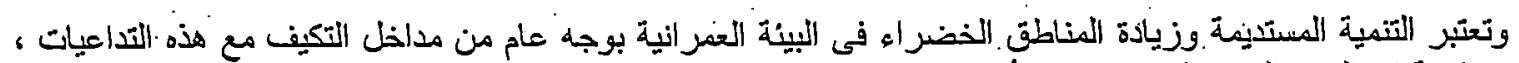

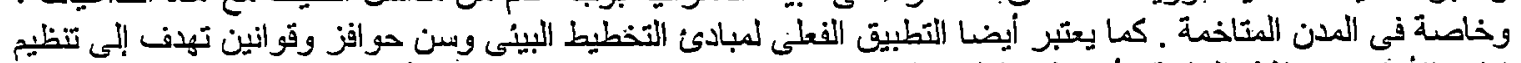

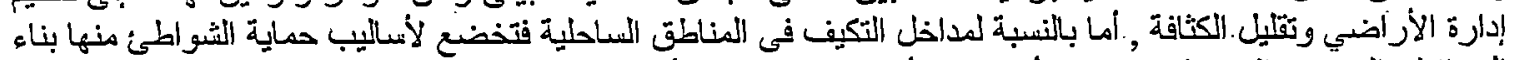

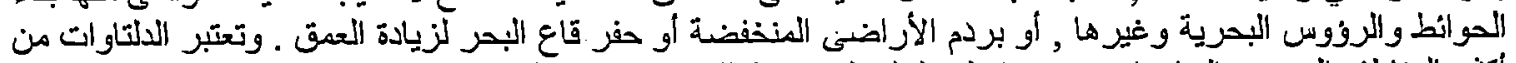

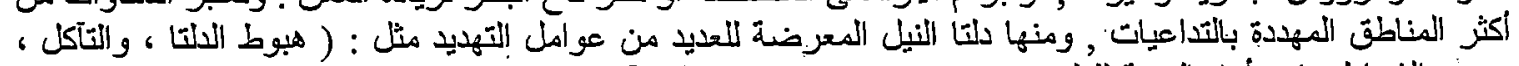

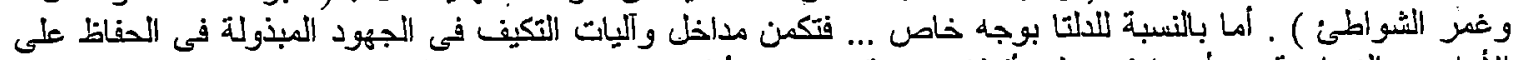

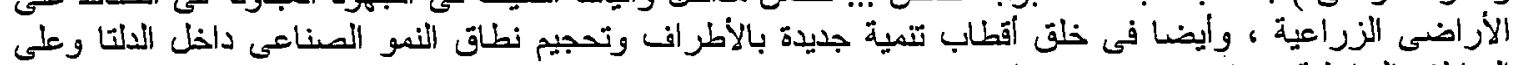

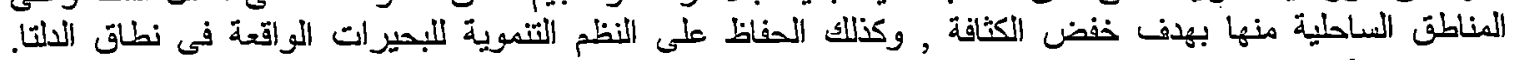


A. 30 Mohamed Salah El Din Sayed El Sayed, Salah Mohamed Ibrahim

Kaooud, Moustafa Mounir Mahmoud and Shereen El-Shahaat Okeel

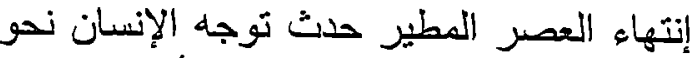

:

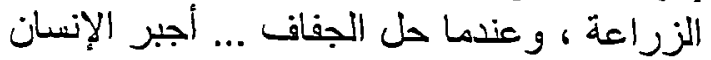
على النزول إلى الو ادى كما بالثكل (1) (1)، ونتج الإنجان

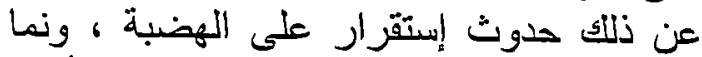

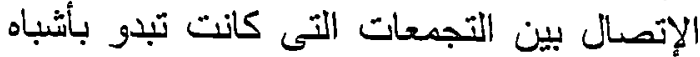

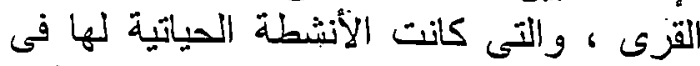

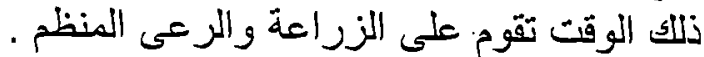

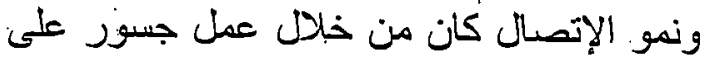
نهر النيل ،ومن خلانل تجفيف المستنقعات وإبنتناس الحيوان .

وخلال عصر ما قبل الأسرأت حدث هبوط فى في

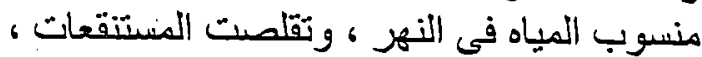
وهو ما أدى إلى اللزحف التى للتمركز والإستقرار

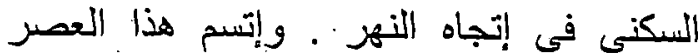

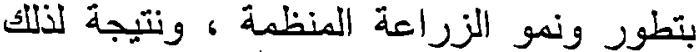

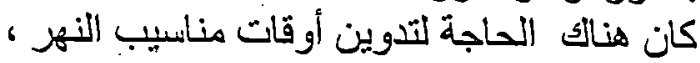

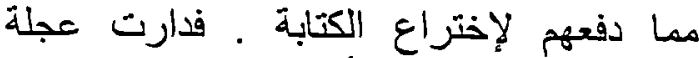

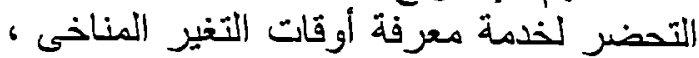
ثم بدأ ظهور الإعمار الحذر على أرض الرض دلتا

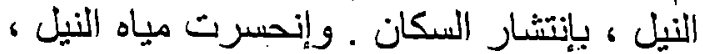

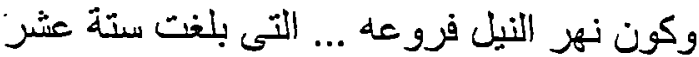
فرعا أو أكثر ، قاعدنها تمتد من السويس شئ شرقا

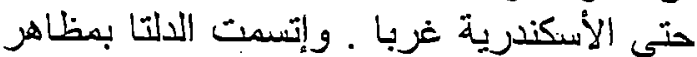

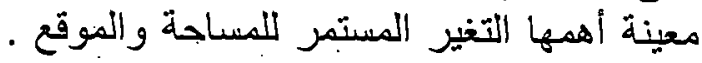

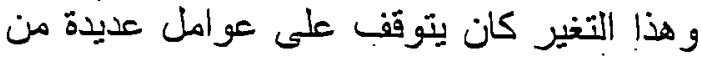

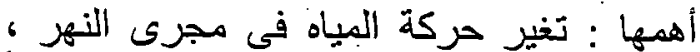

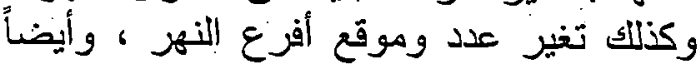
تغير مستوى سطح البحر.

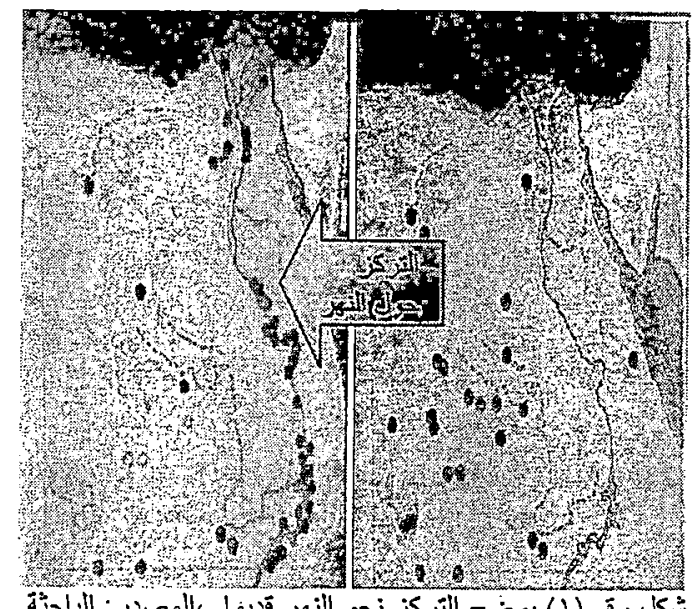

شُكل رقم (1) يوضنح التركز نحو النهر قديفا ،المصدر: الباحئة.

\section{r - دراسة تاريخية لتطوز التفير المناخى وتأثيره على الدارئا

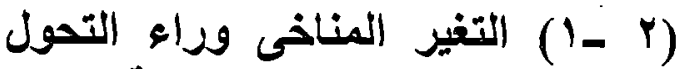

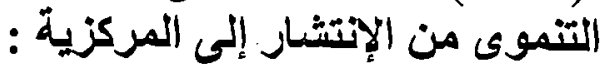

تكون العصر القديم من ملايين السنين فكان هنالئ

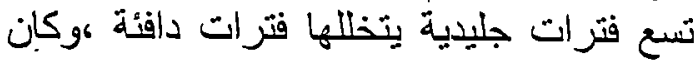

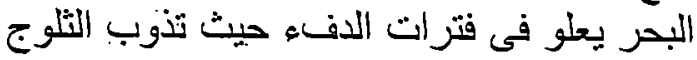

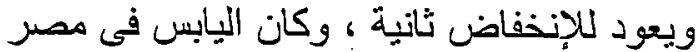

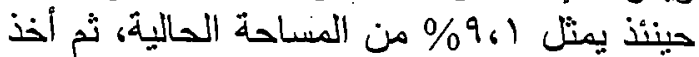

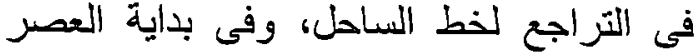

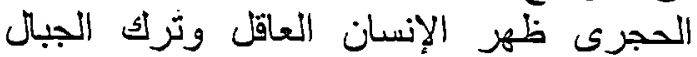
وسعى وراء الغابات والتى يكثر فيها وجود

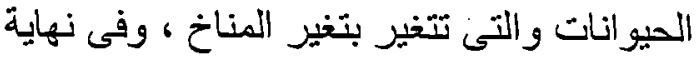

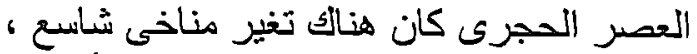

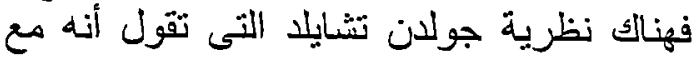




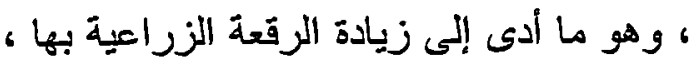

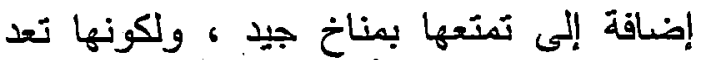

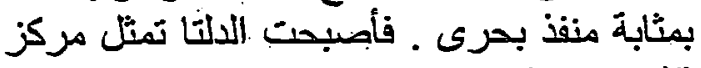

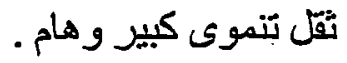

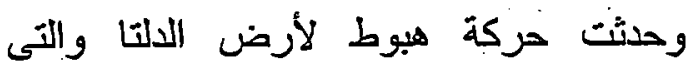

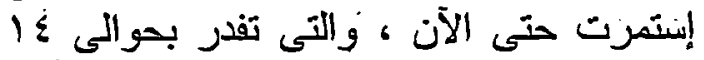

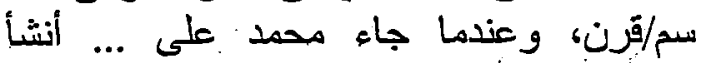
القناطر الخيرية لتذزين الفائض من المياه وبذلكاء

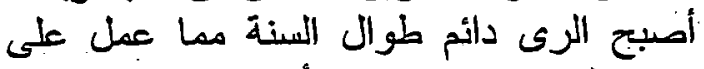

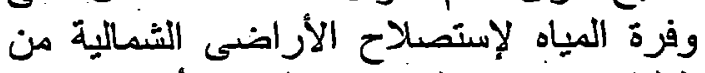

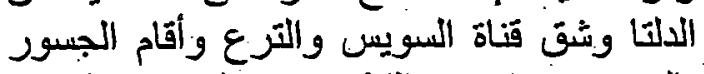

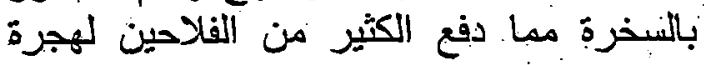

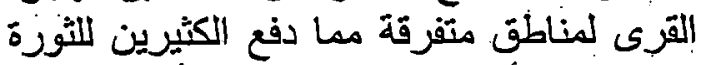
ومان تلاه من أحداث متتالية بيناء سد أسبوان والمبند

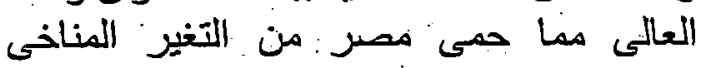
والتوجة التنموى للالتًا .

\section{ب - دراسة تأتثير التغير المناخى على

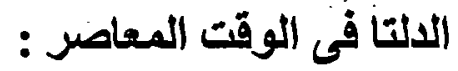

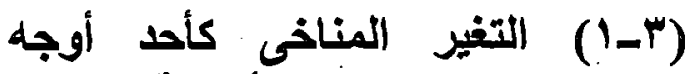 التهديد البيئى للعمران والأنشطنة}

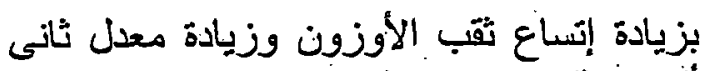

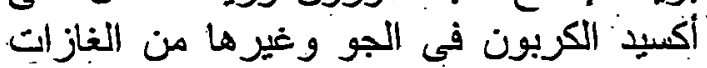

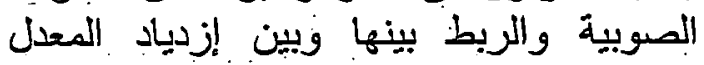

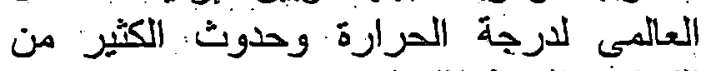

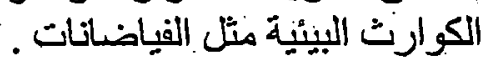

ومن الدلائل على حدوث تغبير مناخى ... الزيادة

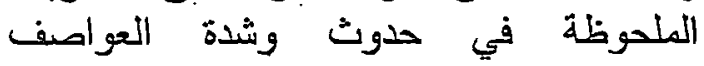

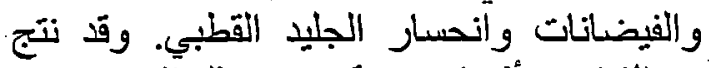

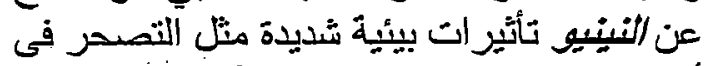

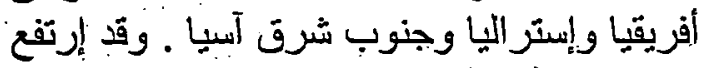

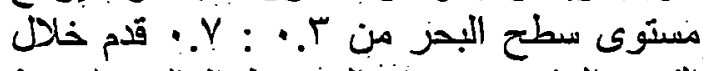

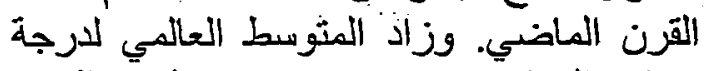

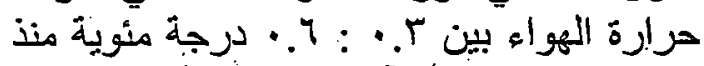
القرن التاسع وحتى الآن.

ونبستنتج من هذا أن مختلف المدن تواجه بالفعل تحنيات مناخية وبيئية بخلاف تنغيز المناخ مثل :

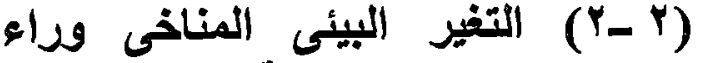 تداعى وإزدهاز التتمية :}

فى فترة الأسرات الفرعونية أدرك الإنسان

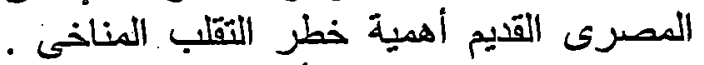
ويعود هذا إلى عدة عوامل أهمها :

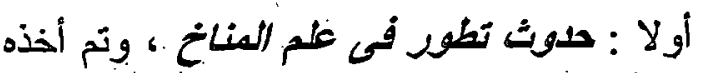

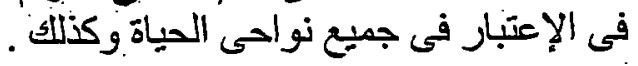

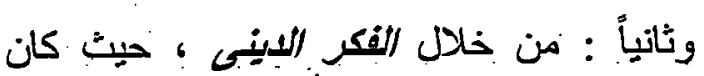

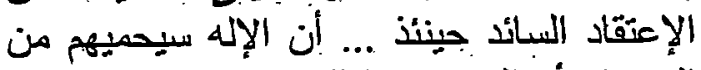

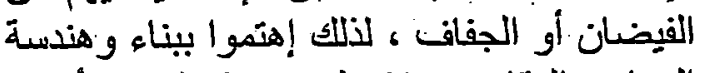

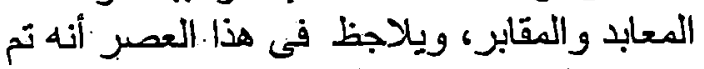

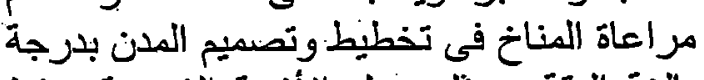

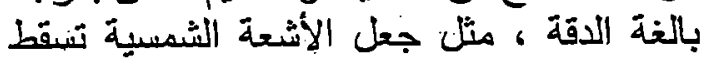
على وجوه التماثيل فى المعابد في أوقات المعات معينة

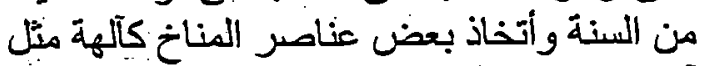

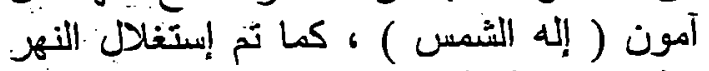

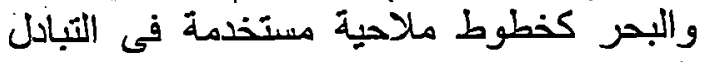

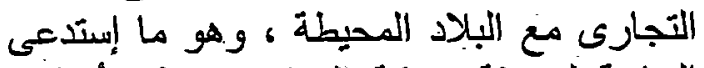

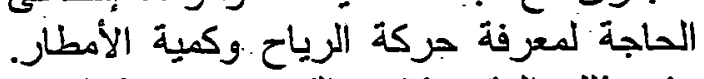

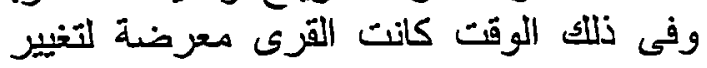

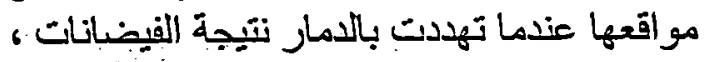

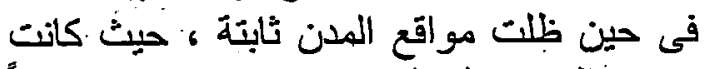

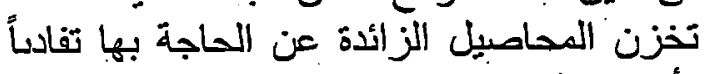

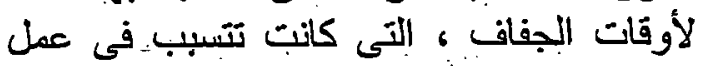

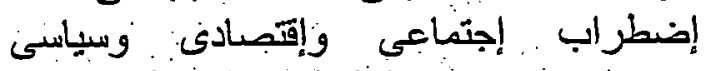

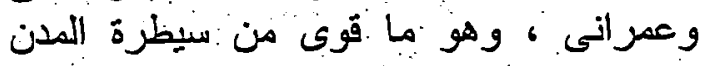

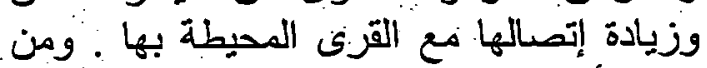

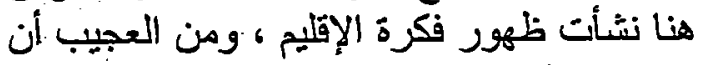

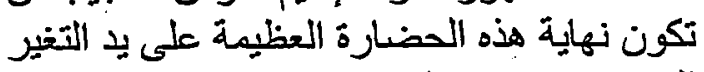
المناخى ، حيث حلت فترة جفارة الفئ عظيمة تسبيت في وجود البطالة والفقر والفوضى فئى في البلاد وأنقلب المواطنين على اليجكام.

\section{(Y-Y) التضيز البئى المناخى وراء التوجه التنموى نحو الدلتا : التائا}

فى قترة عصور الحضارات المتعاقبة المختلفة

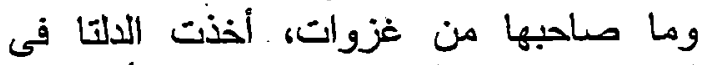

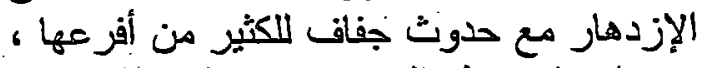
ومع إختفاء معظم المستنقعات وتقلص البحيرات ألرعات 
A. 32 Mohamed Salah El Din Sayed El Sayed, Salah Mohamed Ibrahim Kaooud, Moustafa Mounir Mahmoud and Shereen El-Shahaat Okeel

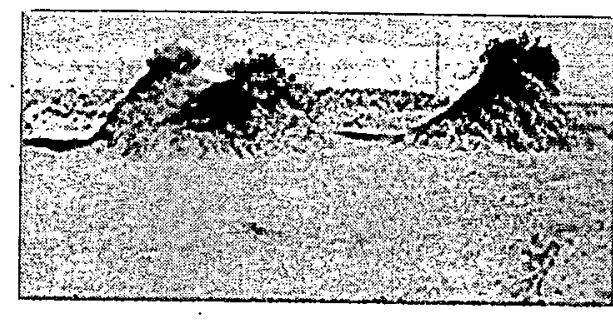

الشكل رقم (r) يوضح تعرية و هبوط الأراضى السلطلية فى الدلتا.

كما أن غالبية أجزاء الدلتا الثنمالية لا بيتجاوز

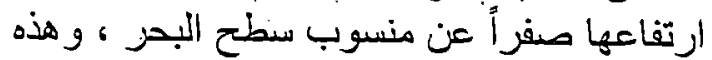

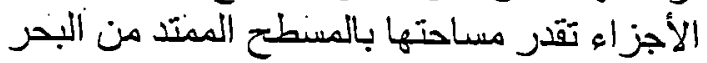

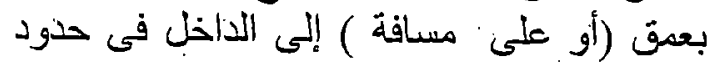

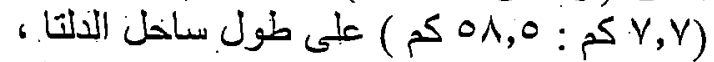

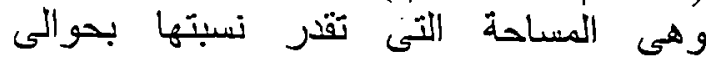

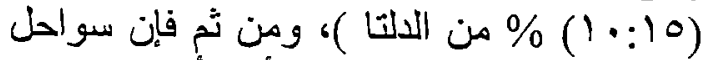

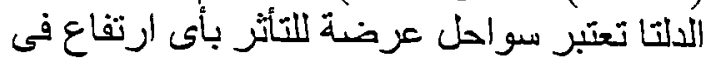

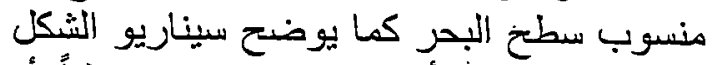

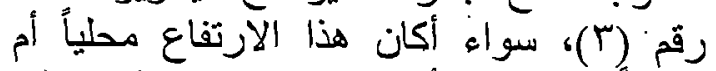

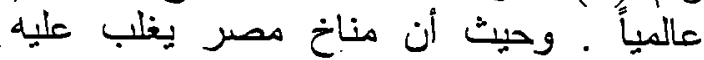
الجفاف ، لذا فمن المتوقع مايلى : ان مناخ مير

ـ حدوث إرتفاع فئ درجة الحرارة ،

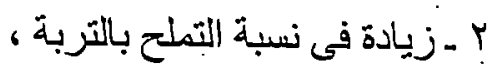
ب ـ حدوث زحف لرمال الصحر اء نتيجة للزيادة

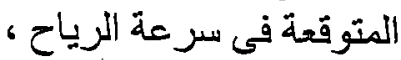

ع ـ قلّة الرطوبة نتيجة لزيادة نسبة البخر . وحميع هذه العوامل ستؤدى المى تصحر أطر اف

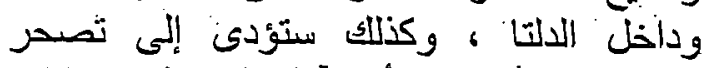

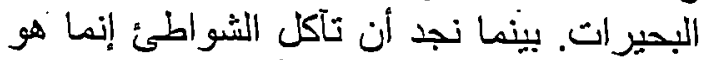

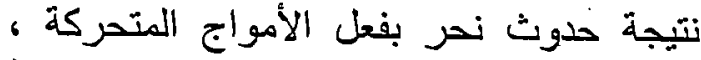

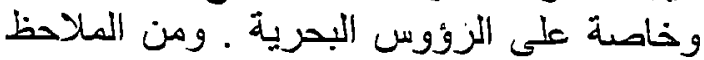

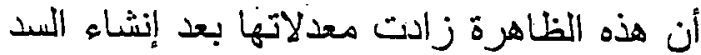

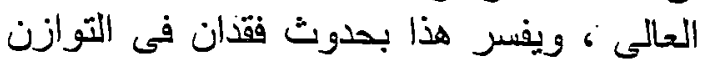

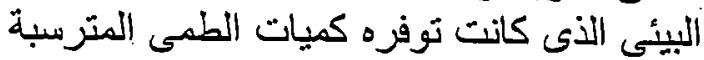

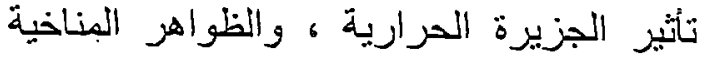
المتطر فة ، مثل العو اصف والتف والسيول.

ودورة التغيزات في المناخ نكون فصحوبة

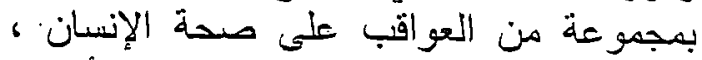

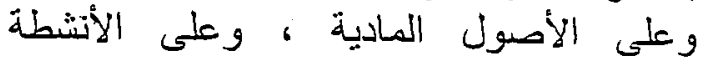

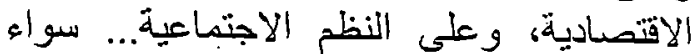

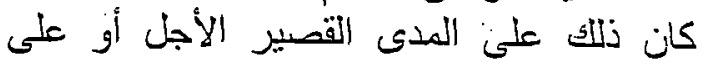

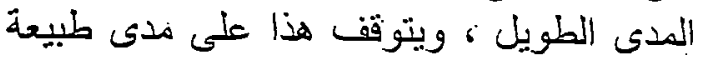
وحساسية النظم البيئية وعلى وكلى استعداد المدينة

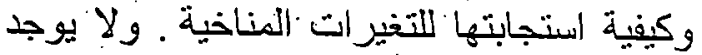

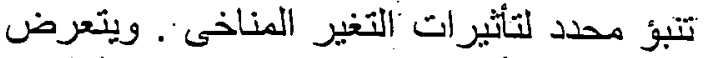

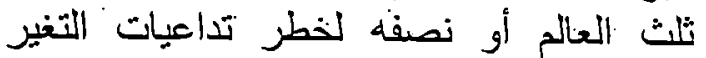

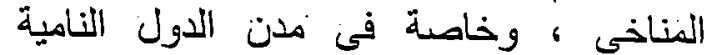

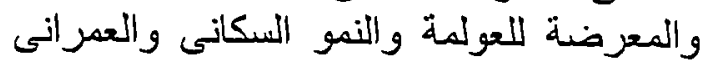

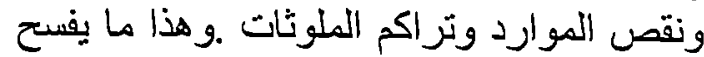
المجال لتوقعات مستقبلية عريضة للتداعيات .

\section{الألتا بين ظاهرتى أرتفاع سطح (r) البحر والتصحر:}

تتركز أكثر . مناطق مصر المهيدة بالاجتياح

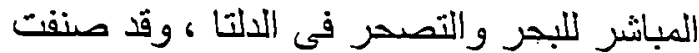

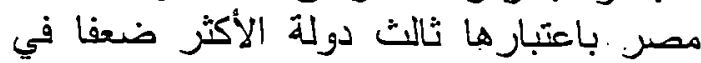

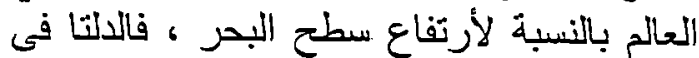

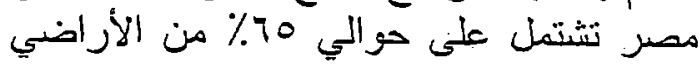

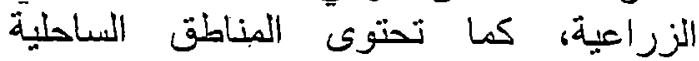

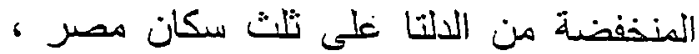

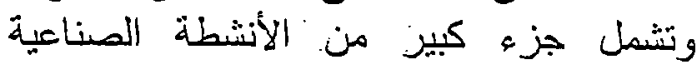

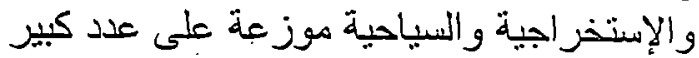

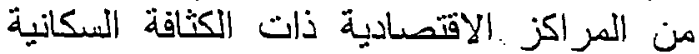

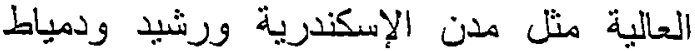

$$
\text { وبور سعيد. }
$$

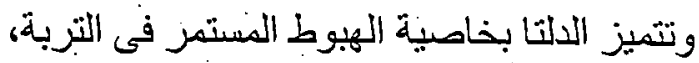

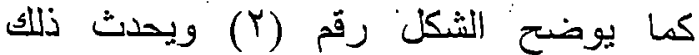

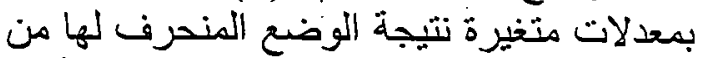

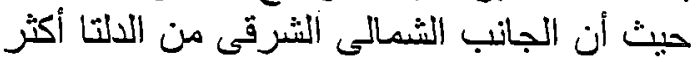

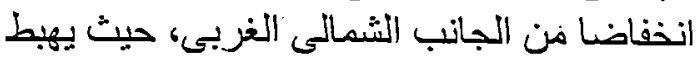

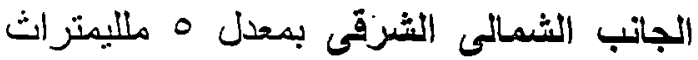

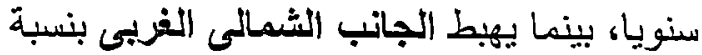

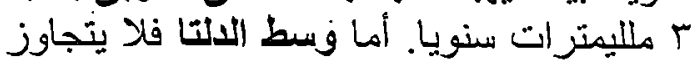
معدل الهيوط ع , · ملايمتر سنويا. 
الأمن البشرى ، كما أنها بسوف تؤدى إلى زئى زيادة

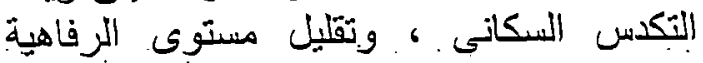

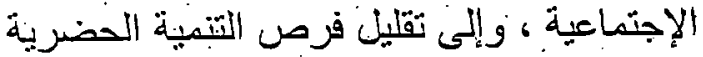
الساجلية.

\section{ـ ـ آليات ومداخل التكيفت مع التقيز المناخى فئ التخطيط :}

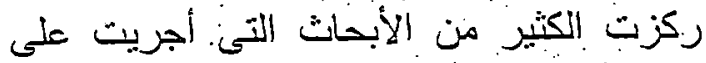

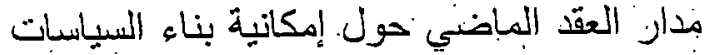

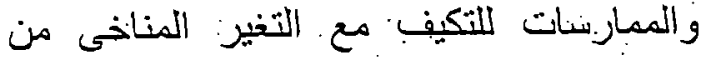

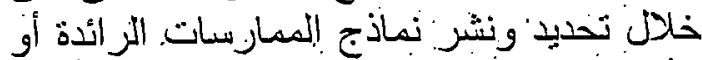

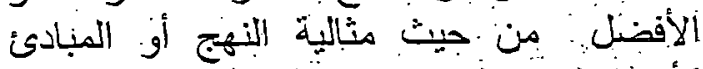

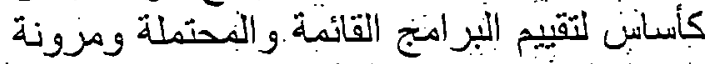

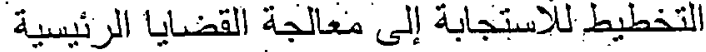

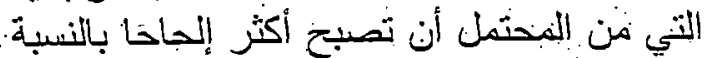

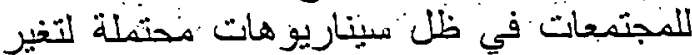

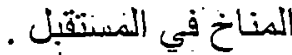

ويراعى في إلنخطيط أن بكون .الهدف من

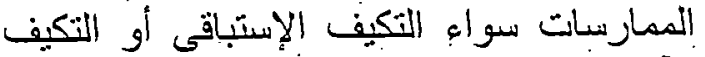

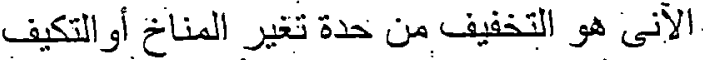

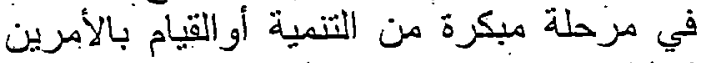

\section{: التخفيف واستراتيجياتها: (1-1)}

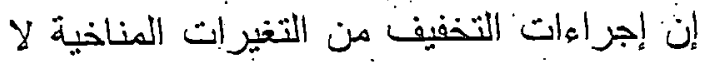

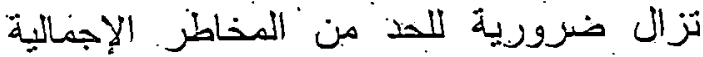

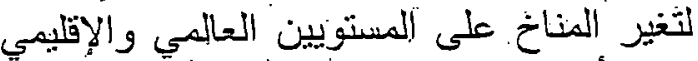

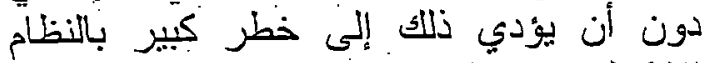

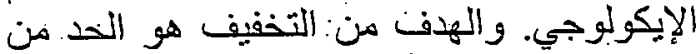

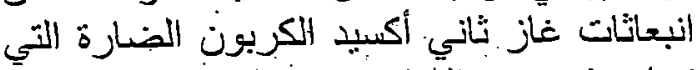

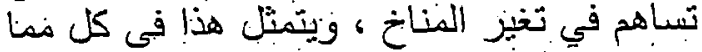
يلن :

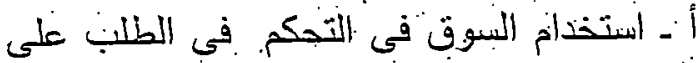

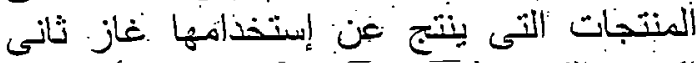

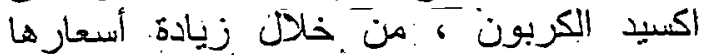
وبالتبالي خفض الطرنون الطلب عنيها. بـ ـ تطبيق المجاييز إلبيئية و.قو انين البيناء .

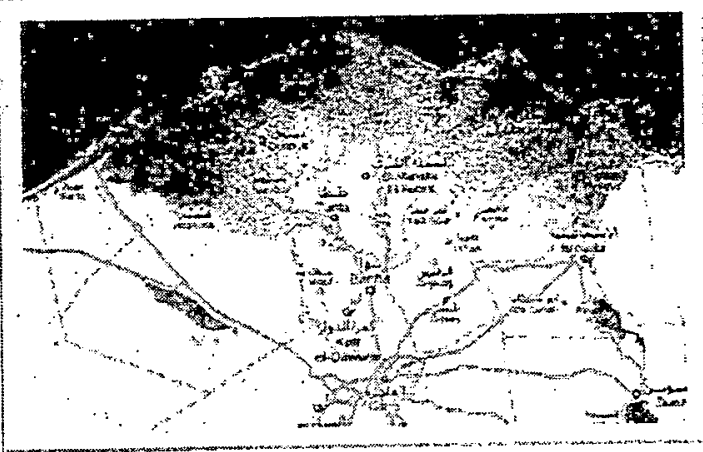

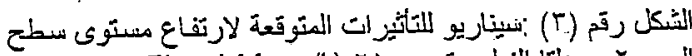

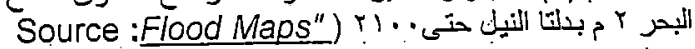

(mashup

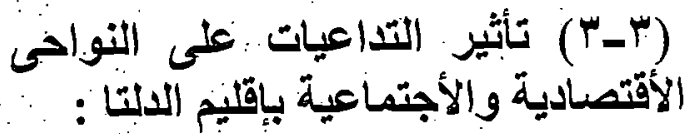

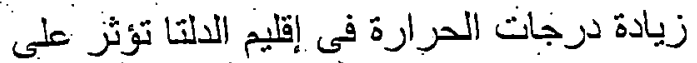

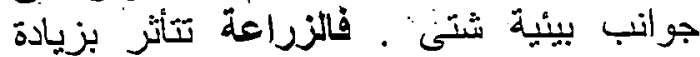

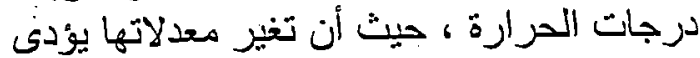

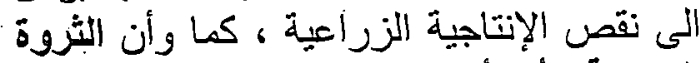

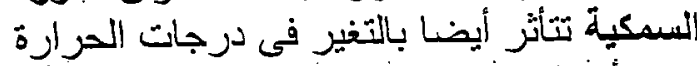

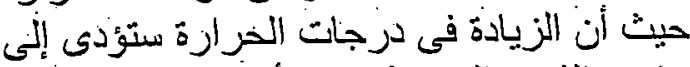

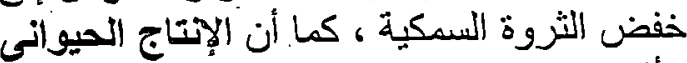

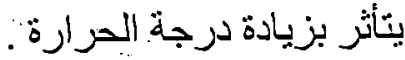

بالإضافة إلى ذلك ... ستؤدى تداعيات التغيرات

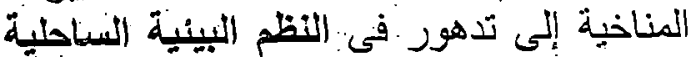

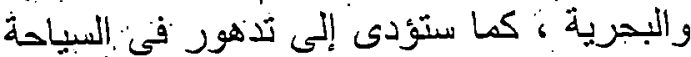

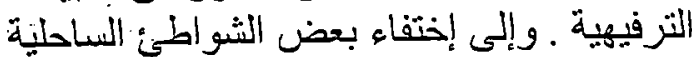

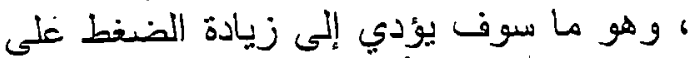
المناطق السياحية الأخرى .

أما عن مصادر الطاقة فسيزيد الطنب عليها. بزيادة درجات الحرارة مناد مالرة

ونتيجة لجميح مظاهز التاثير على الجوانب:

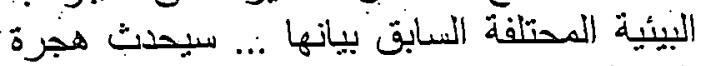

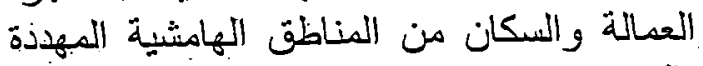

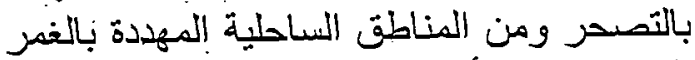

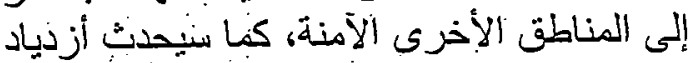

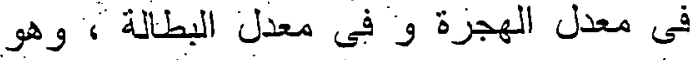

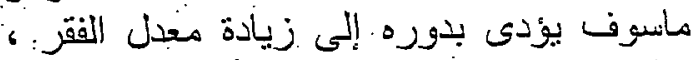

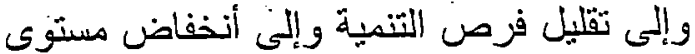


A. 34 Mohamed Salah El Din Sayed El Sayed, Salah Mohamed Ibrahim

Kaooud, Moustafa Mounir Mahmoud and Shereen El-Shahaat Okeel

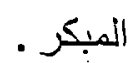

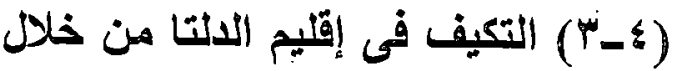 صنع السياسات والخطط :}

يلعب القائمين بأعمال تخطيط المدن دورا رئيسيا

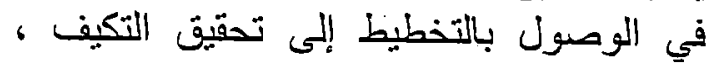

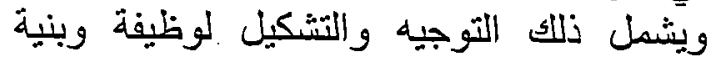

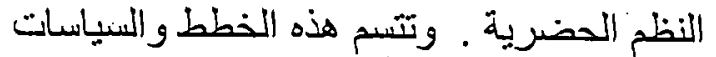

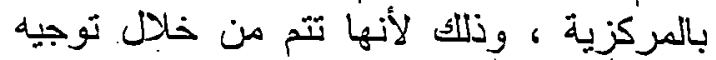
السياسات الصادرة إلى سلطات التخطيط المحلية أو الإقليمية ، مع توفيل إلى دعم للأنظمة القردية الفية الفية

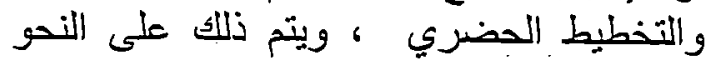

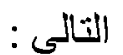

• توفير إطار استراتيجي واضتح للتخطيط السليم ولتحقيق التتمية ألمستدامة خلال مدة الخطة

وضع الرؤى الضرورية في مجال التنمية الني تنتطلب خطط خاصنة.

إعطاء الصبخة المكانية لأهداف التخطيط. توفير توجيهات واضحة الفئة للقائمين بأعمال التطويز و إلى هيئة التخطيط في تقيبيم هذه المقترحات .

\section{(\& ـ ـ التكيف فى إقليم الالتا من خلال التصميث :}

وهنا يبرز دور التخطيط في تعزيز وتوسيح

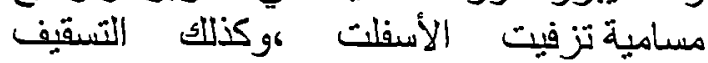

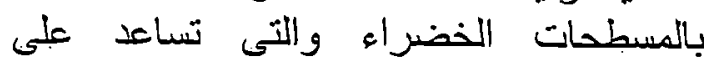

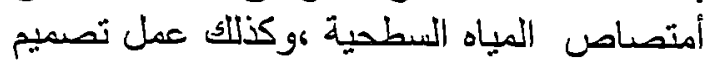

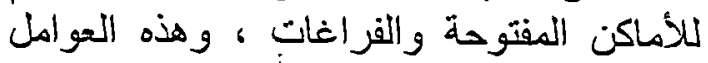

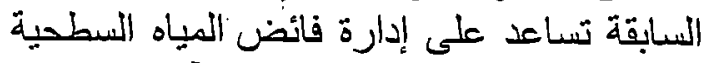

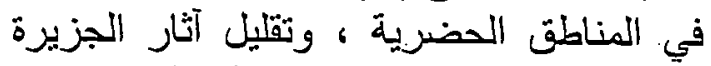

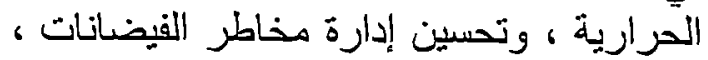

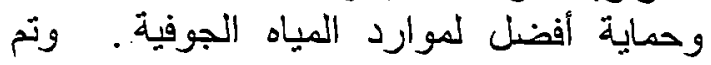

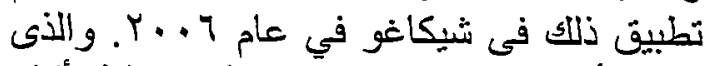

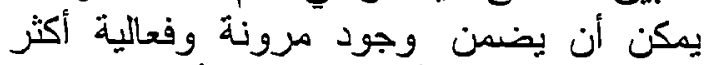

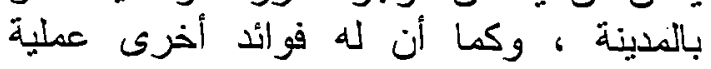

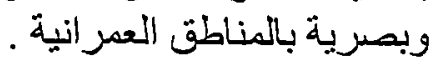

ج ـ الإدارة الجيدة ودور ها فى التحكم فى تلبية الاحتياجات اللازمة من (الطاقة والمياه) ؛ نسواء في تلاء

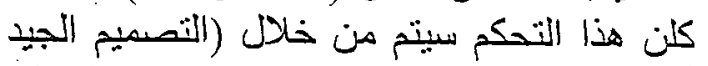

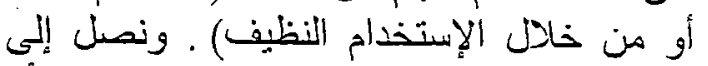

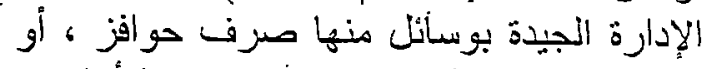

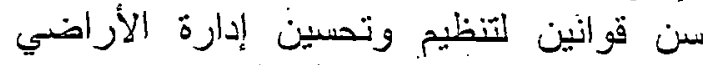
و الغابات ووضح لوائح لتنظيم المياه .

\section{(צ- (Y) مبادئ للمبمارسات كخطوة أولى نحو التكيف بالأقليم : بليمادي}

دعم مبادئ التنمية المستدامة بيئيا في التصميم المنهجى للتكيف و التخفيف ، بما فئي في في التئي ذليك السلامة البيئية والعمر انية ومع مراعاًة

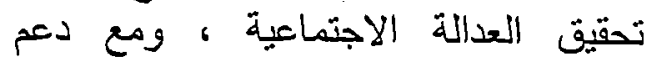

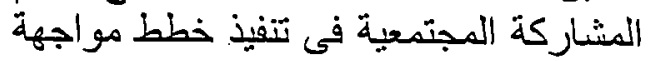

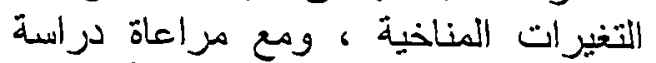

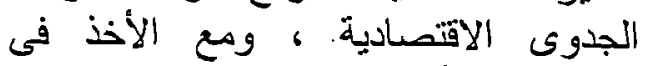

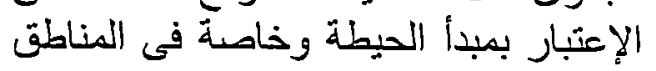

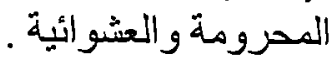

إعطاء الأولوية لإتخاذ إجراءوات مناسبة

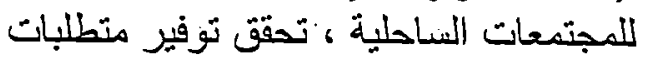

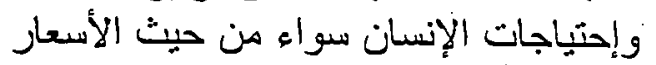

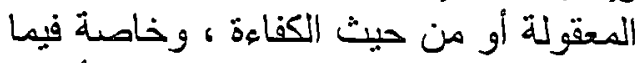

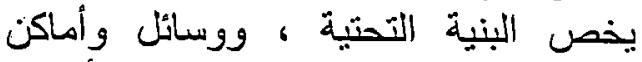
الثرفيه. والراحة الطبيعة بما في ذلك الأنشطة ألسياحية. استخدام قاعدة بيانات وأدلة سليمة،

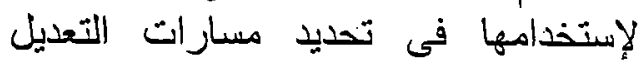
والإستجابة من التخطيط المرن لمواجية المهاري التغير المناخى. ضرورة تناغم آليات التكيف مع تغير المناخ

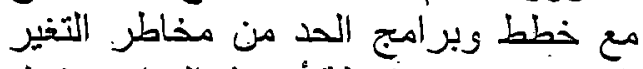
المناخى ـ مع ملاحظة أن هذه البر امج تشمل

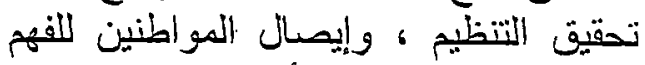

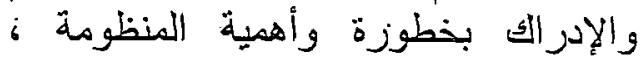
وتخصيص ميزانية تستخدم وقت الضرورة الضئرة

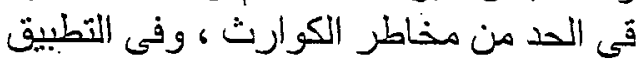

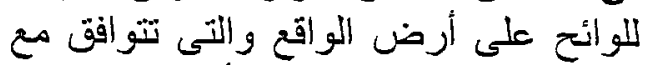

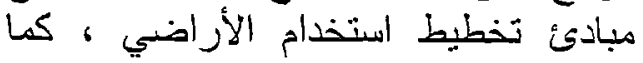
تستخدم هذه الميز انية في نركيب نظتم الإنذار 


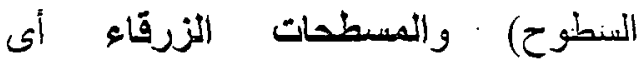

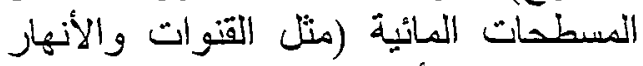

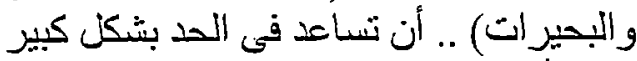

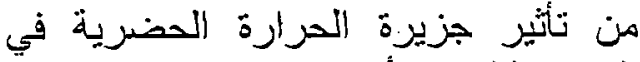

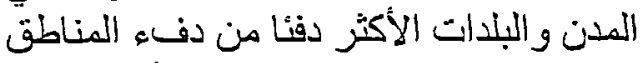

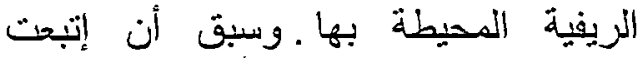

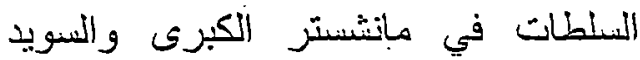
ومجلس ملينة مالمو ... تطبيق هذا الأسلوب واستخدامه في تطوير الواجهة البحرية.

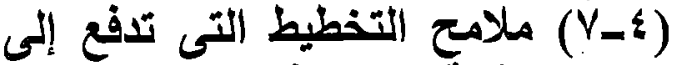

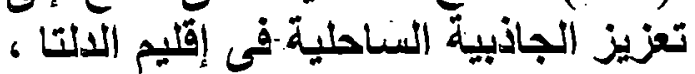
والتى تدفع إلى التكيف مع تغير المناخ : فئل

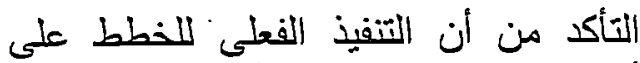

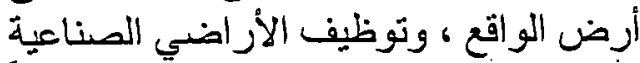
وألسياحية والسكنية في مناطق أقلَّل تعرضاً

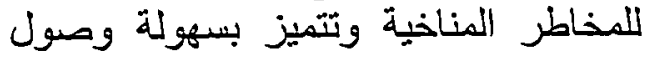

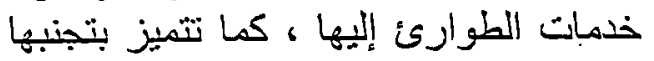

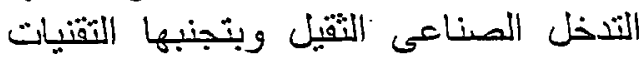
المجهولة العو اقب .

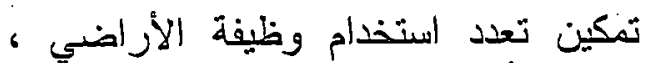
شريطة أن لاتكون الاستخدامات الإضاّفية تهذد الجودة على المدى الطويل ــ ومن أمثلة الإنة الإستخدامات الإضافية تضمن اللامركزية للطاقة أى (عل محطات توليد الطاقة مثل الإنل

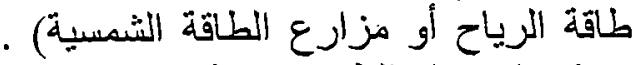

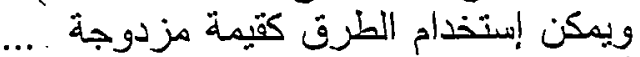
أى كمسار للتقل وكسدود . التأكد من نطبيق معايير التصميم في المدن التئن

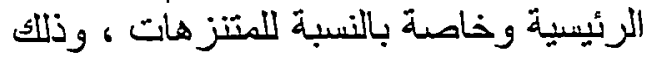

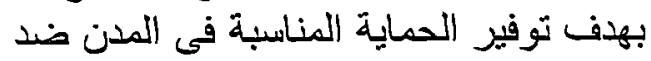

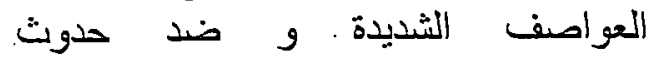
الإعاصيز . ويجب أختبار المواقع التى لئى

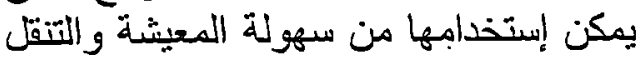
بالنسبة للمقيمين ، والإخلاء الآمن فى حالة

$$
\text { حدوث كوارث. }
$$

أعادة هيكلية العوامل الموجهة للتصنيم الحضري وتضمين قو انين البناء بما يزيد النيد من النسائم الطبيعية و التبريد الداخلي اللباني لئى

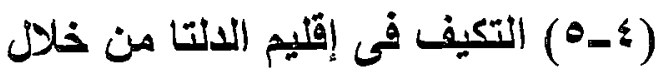

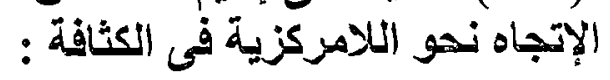

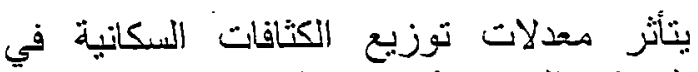

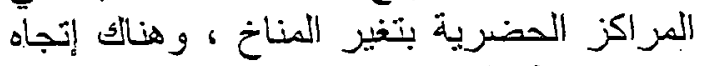
نحو سياسنة اللامركزية اثى التُوسع والإنتثار

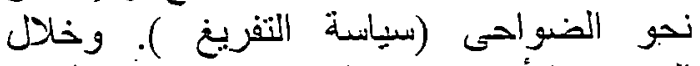

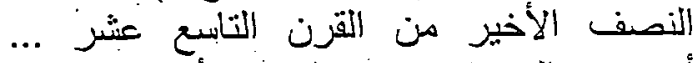

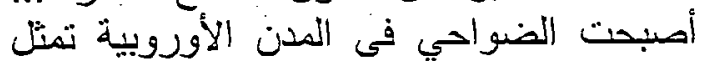

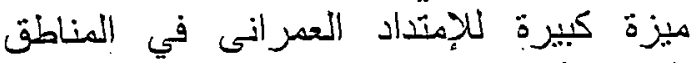

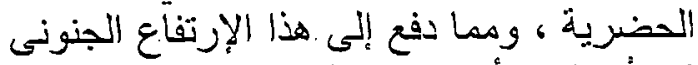

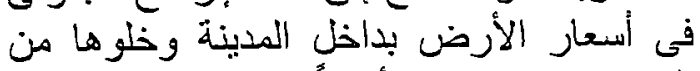

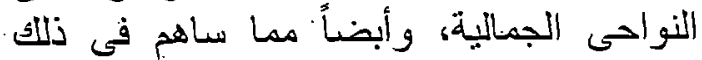
ظهور الازدحام الثنديد فى مناطق وسط المدن.

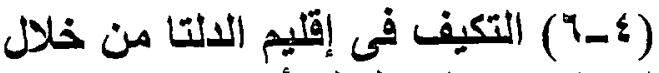

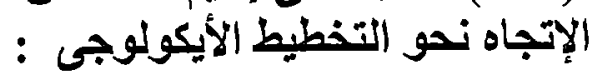

عند القبام بوضع إستراتيجية يتم من خلالهها

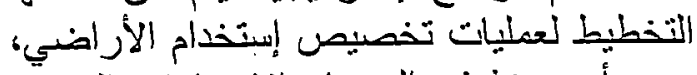

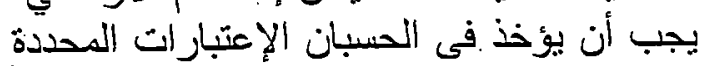
التالية :

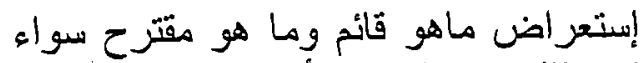

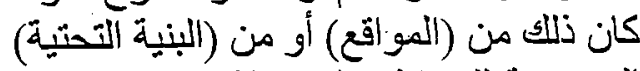

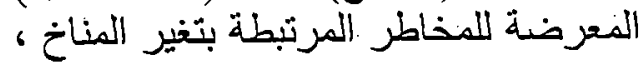

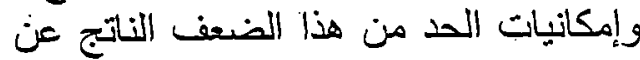

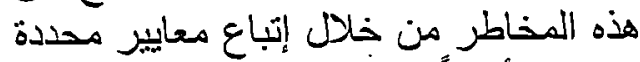
للابناء ، وأيضاً إتباغ ضون ابط محددة للتنمية.

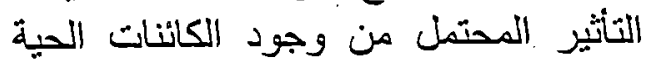

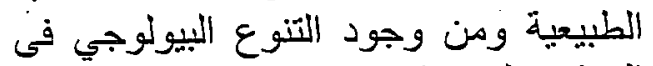
الموقع على تركيب وتكوين تنمية التجمعات المئ العمر انية القائمة . ضرورة أن تضمن مخططات التجمعات

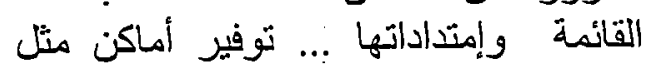
الطرق والساحات على سبيل المثال والتى لتى

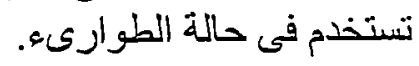
خلق البيئة العمرانية التئ من شأنها التعامل

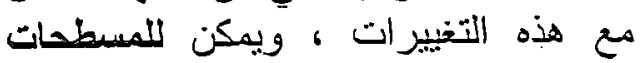
الخضراء (مثل الحدائق والغابات أو على لميط 
A. 36 Mohamed Salah El Din Sayed El Sayed; Salah Mohamed Ibrahim Kaooud; Moustafa Mounir Mahmoud and Shereen El-Shahaat Okeel

مراعاة تصريف مياه العواصف و الأعاصير للحد من الكوارث البيئية المحتمل حدوثها نتيجة ذلك . لكن الكرار مراعاة تأثير التتمية على الحد من تخزين مياه الفيضانات وزيادة مستويات القيضدانات وسز عات التدفق . مراعاة الظروف (البيئية ، والعمرانية ، والئية والإجتماعية ، ، والإقتصادية) اللمنطقة

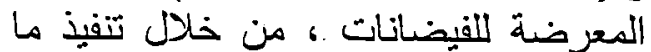
يتناسب من أعمال هندسة حماية الشواطئ تلفئ

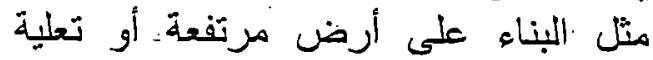

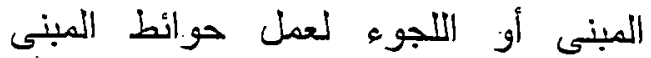

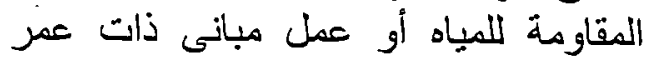
أفتر اضىى قصير ، وبتكلفة إقتصادية ضعيفة.

\section{: حواجز التكيف (^)}

• المناخى.

عدم اليقين بشأن توقيت ونطاق بعض النأثير ات لهذه التدأعيات .

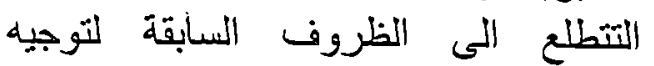

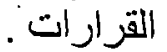
التركيز. على المدى القصبر لتكاليف التكيف

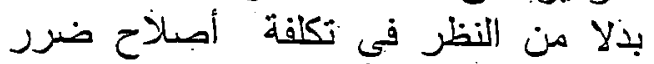
التداعيات طويلة الأجل. صعوبة الحصول .على اهتمام والتزام القادة السياسيين . صعوبات في الحصول على بعض أصحاب المصلحة الى مناقشات التكيف . مشاكل الثتسيق بين الإدارات الحكومية الحية

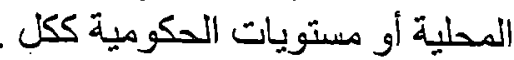
عدم كفاية الموارد لمواجهة التداعيات . لمكية .

\section{(8-9 ) أوجه الأستفادة من التجارب العالمية}

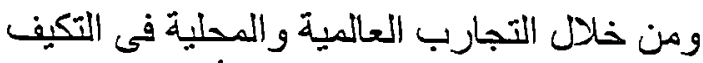

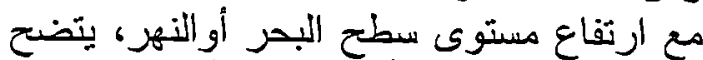
أن التجربة الهولاندية كانت من أنجح التجارب النيح
ه تصميم أراضى الفضاء العام للتصدي لأشد المند

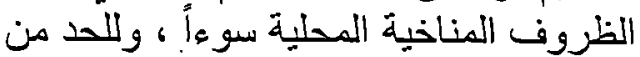

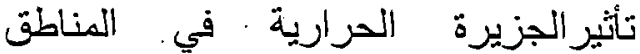
الحضرية ، ويتطلب ذلائك مايلى : الئل أ ـ التوسع فى إستخدام التظليل بإبتخدام النباتات الملائمة ، وذللك لتبريد المساحات المبات

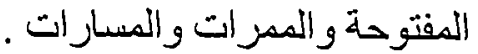

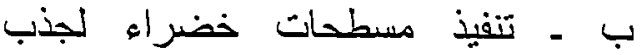
وإمتصاص مياه الأمطار ولمنع سريان المياه السطحية. ج - إعادة النظر في طرق تصميم المرافق المقالق

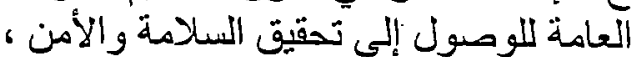

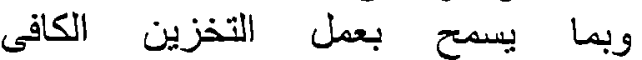
للإحتياجات خلال الأحداث العاصفة التى يمكن أن تحدث فجأة فى أى وقت.

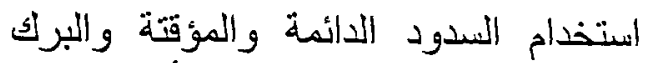
ليس فقط لحجز المياه ، وإنما أيضا بهذف ولئف حماية التنوع البيولوجي. دعم الأنثنطة الاقتضادية البيئية المختلفة (كصيد الأسماك ، و السياحة ، والملاحة).

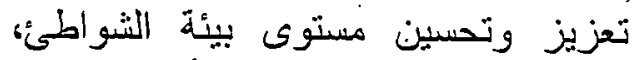

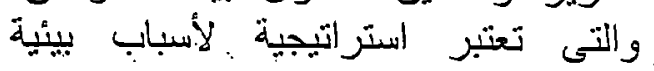
وسياحية.

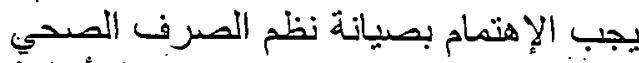
لمواجهة القيضانات ، وضرورة. عل أنظمة تحذير مسبقة.

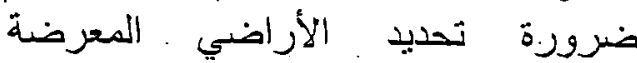

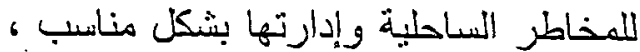

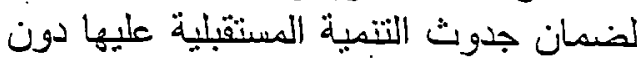

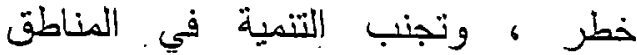

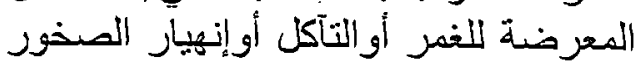
أو المتربة.

مراعاة تجنب الأخطار المحتبلة هن النمارية

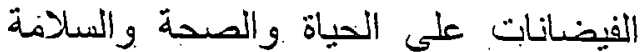

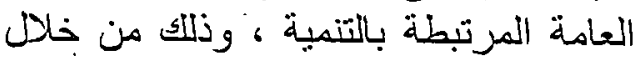

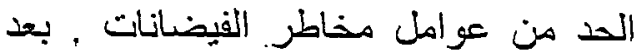

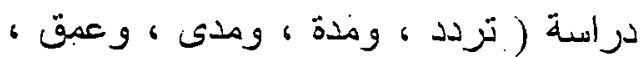

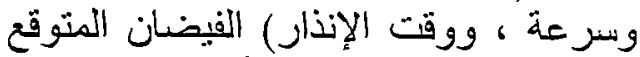

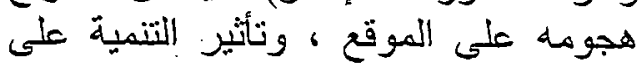
توجيه مباه الفيضان . 


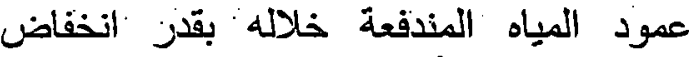

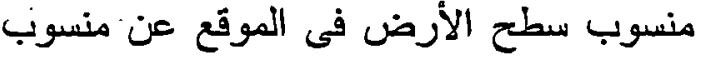

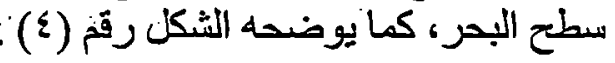

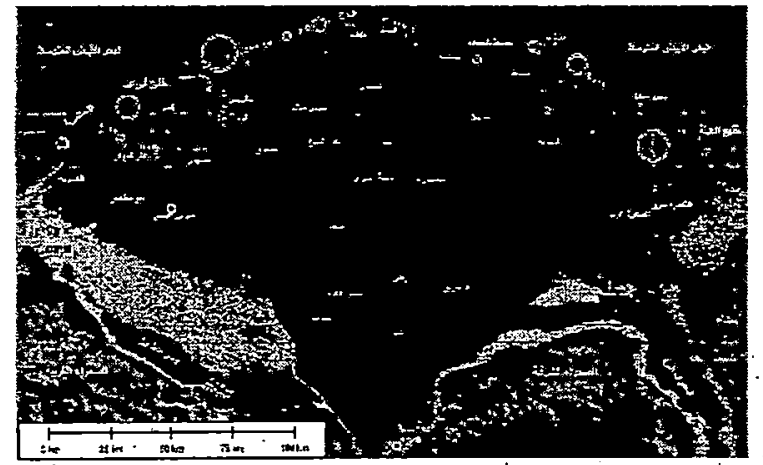

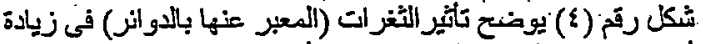

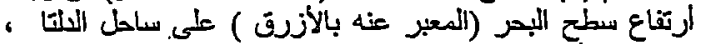

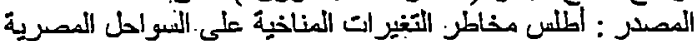

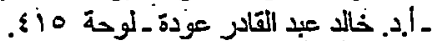

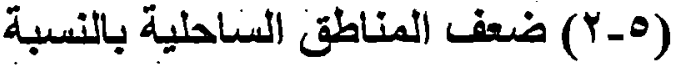 لإرتفاع سطح البحر :}

ومن المتوقع أن كل من (التغير المناخي

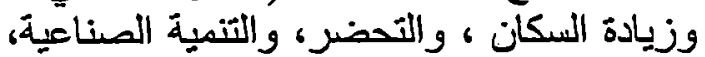

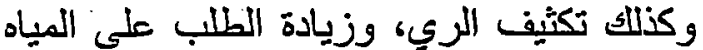

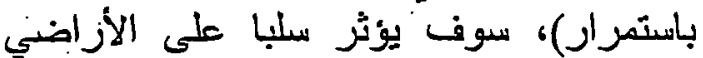

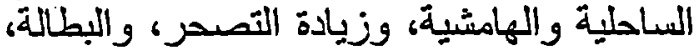

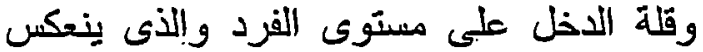

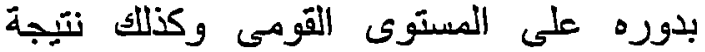
الاضطر ابات السياسية التى من المتوقع حدوثئها

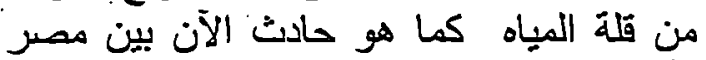
وأثثيوبيا. وتعتبر مدينة بورسعبد والأسكندرية هين الأني

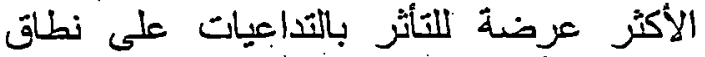

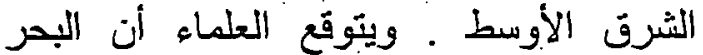

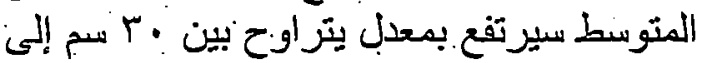

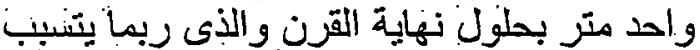

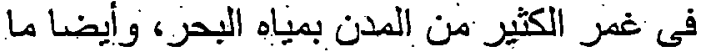
يساعد هذا الخمر نظام تصريف البنية التئية التحتية

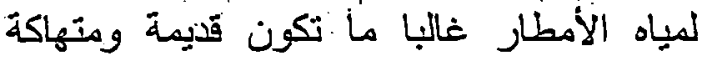

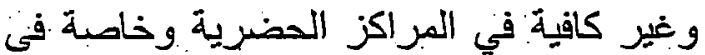

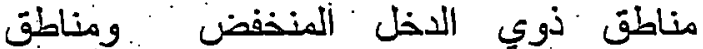

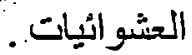

و المدن الساخلية بالدلتا تتطلب العبيند من معايير

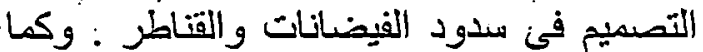

على المستوى الدولى فى هذا المجال،، والتى

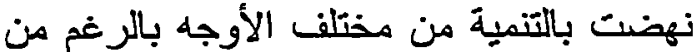

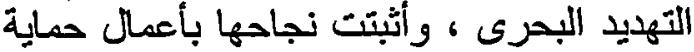

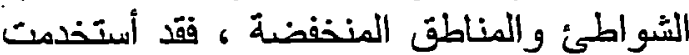

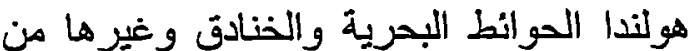

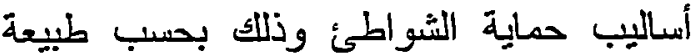
ومقومات كل منطقة. في حين أن التجرية

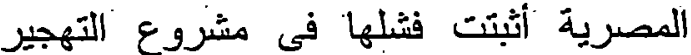
التوبى، فبالر غم من حماية مشروع السد العالى فئى فئى

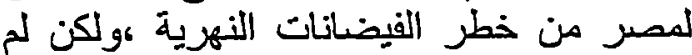

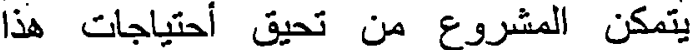

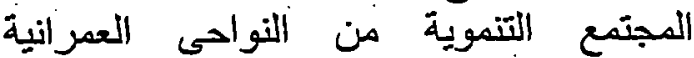

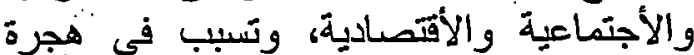

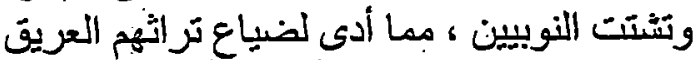

0 - أوجه : الضعف وتقييم المخاطر

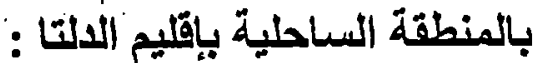

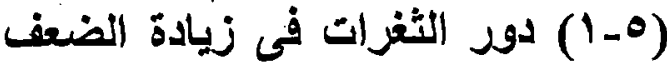
الدالتوى : النوى

يرى الكثير من العلماء وخاصة الدكتور خالد

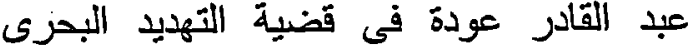

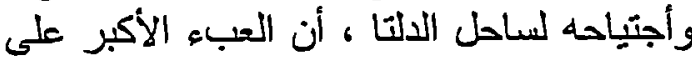

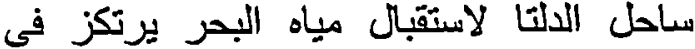

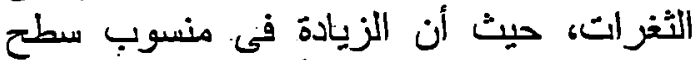

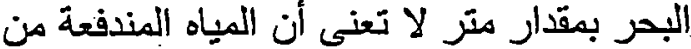

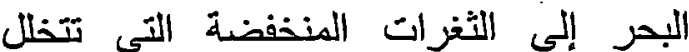

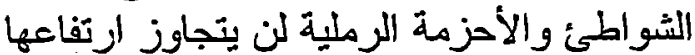

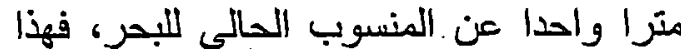

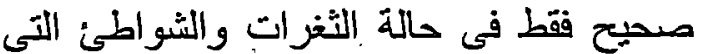
يرتفع منسوبها عن منسوب سطح البحر الحالى.

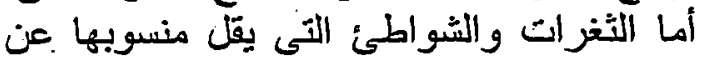

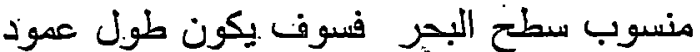

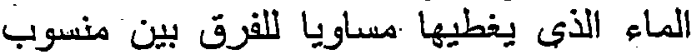

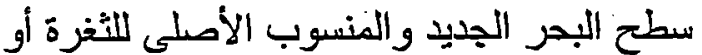

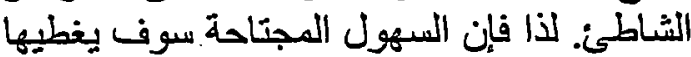

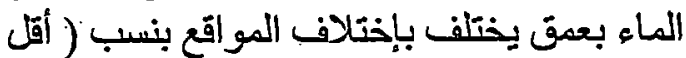

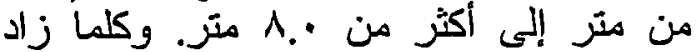

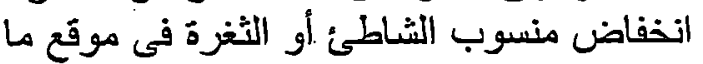

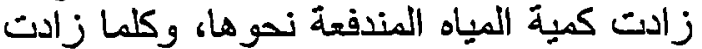

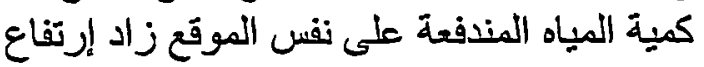




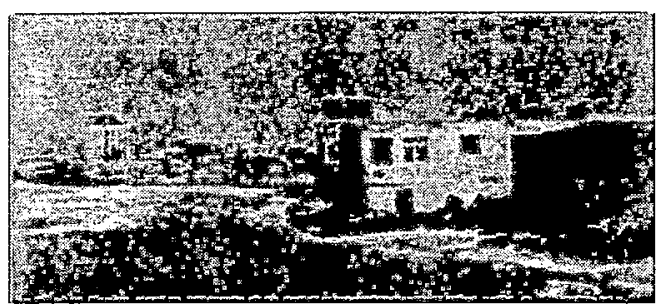

الشكل رقم (0) يوضح تآكل ساحل رثنيد وتهديد العمران القانم بالغزق

ورغم المشاكل المثرتبة على الكثبان الرملية

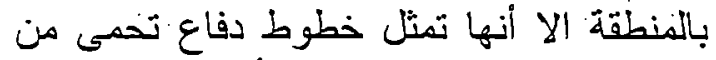

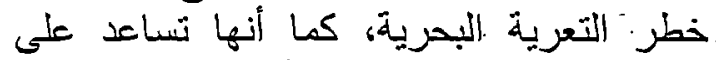

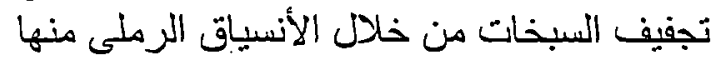

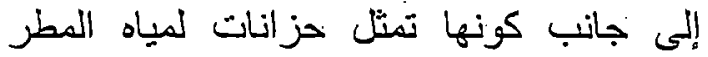

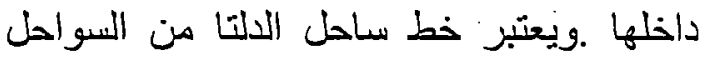

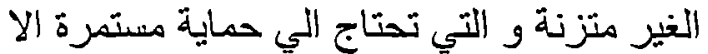

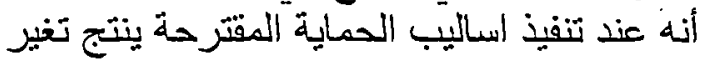
جديد في شكل خط الساخل فيجب استمرارية

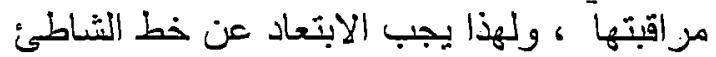

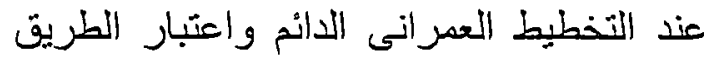

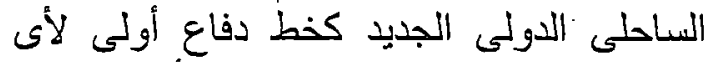
تنمية داخلية جنوب هذا الطريق أما المنطقة أولى المبات

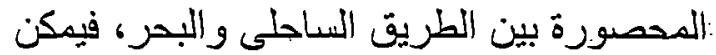

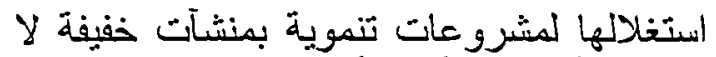

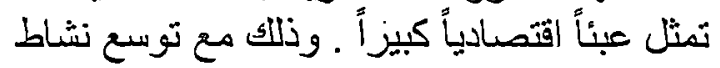
الإستصلاح حيث تم إستصلاح معظم السباخات

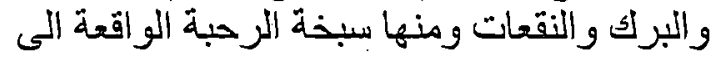

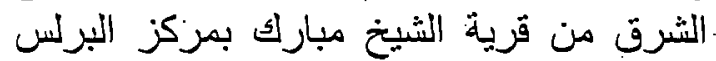
وقد تم تجفيفها بطبقة رملية منة ـ ومن مناطق

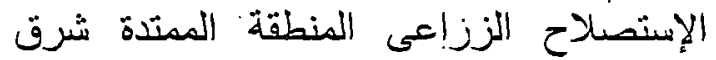
بحيرة البرلس في منطقة الخاتشعة ومنطقة

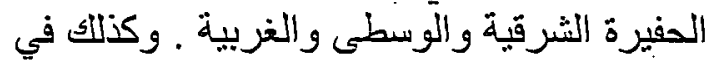

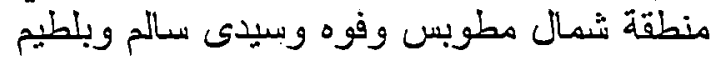

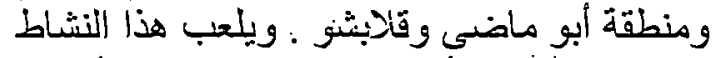

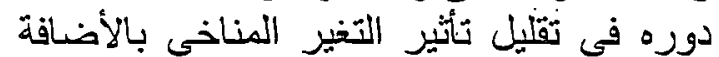

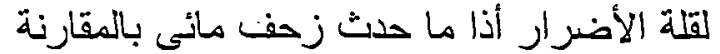

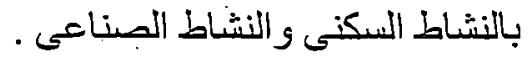

ومن الآثار السلبية التى ترتبط بإرتفاع الرطوبة

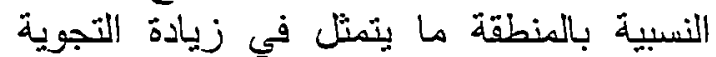

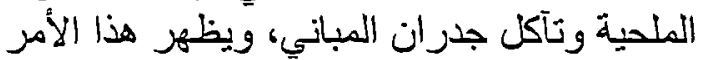

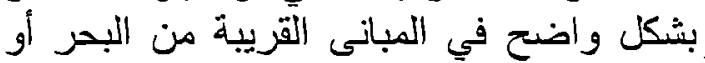

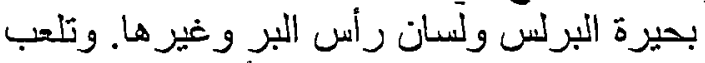

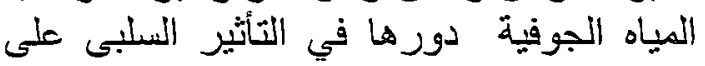

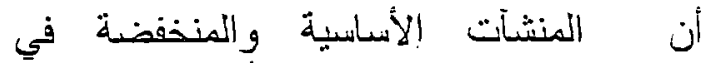

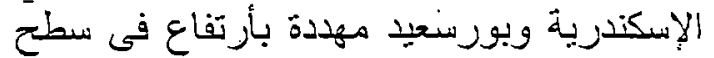

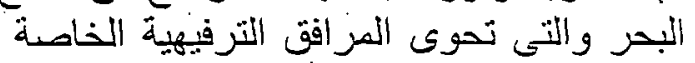

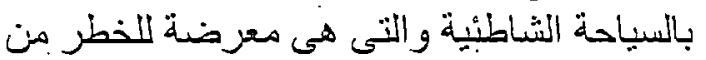

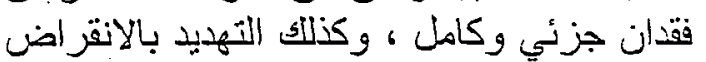

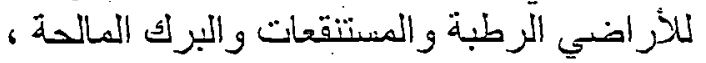

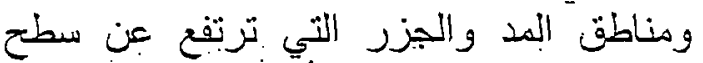

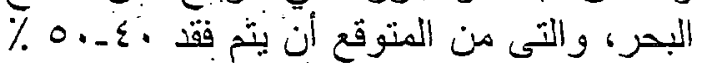

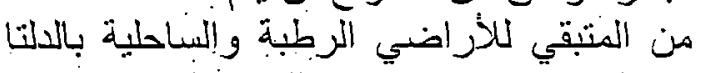

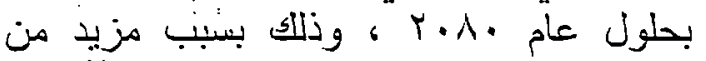

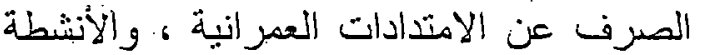

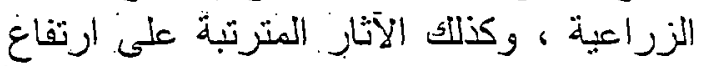
مستوى سطح البحر أنة منر .

\section{(ب-0) :}

وقد ظهرت أثنار التذاعيات الضارة على المباني

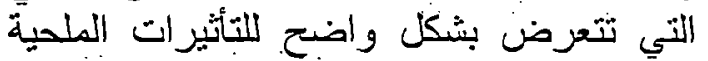

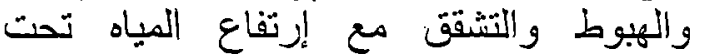
الأرضية بإتجاه أساساتها وتبخز التبر المياه ونترك

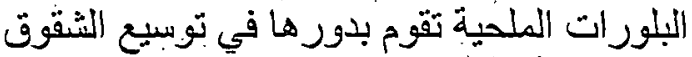

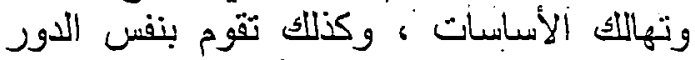

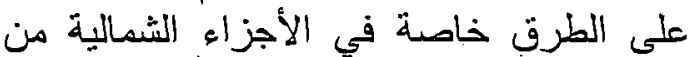
نواحي الحدادى والروضية والئية والأبجادية البحرية

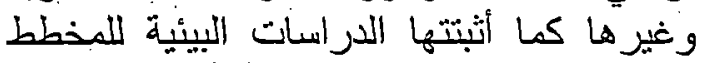
الأستر اتيجى لنشمال الدلتا.

ورغم أن السناحل الالتاوى ككل مهدد بعمليات التعرية البحرية إلا أن هناك مناطية مئن معينة

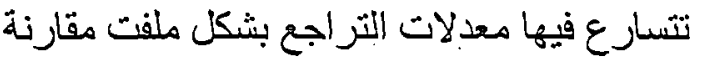
ببقية الساحل مثل منطقة مصب رشي رشيد و منطقة

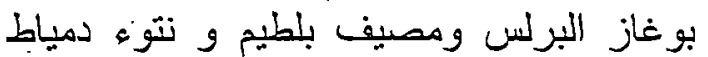
وساحل رأس البر كما يوضح النبكل رقم (0).أما

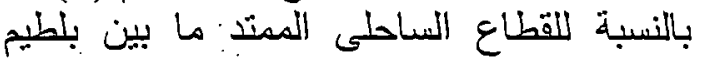

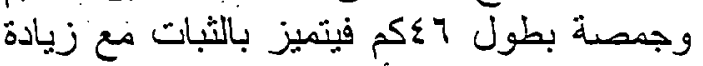
معدلات الترسيب بالأقتر اب من مصيف جمين فصدة 
سبيل المثال يتطلب تقيبم الأثر النيئي (EIA)

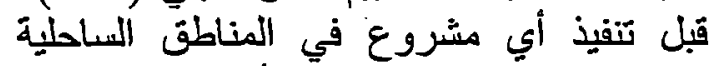

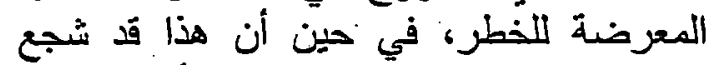

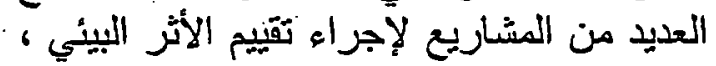

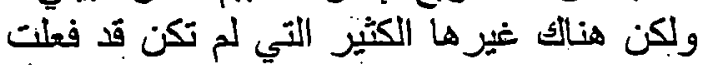

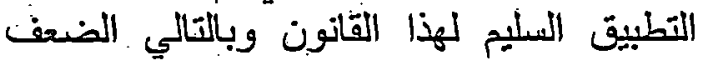
الحرج للإدارة الساحلية.

وهناك أيضا حاجة إلى رصد إبتخدام

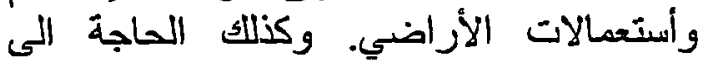

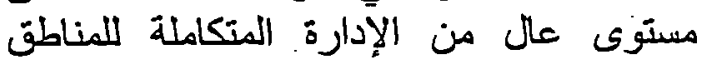

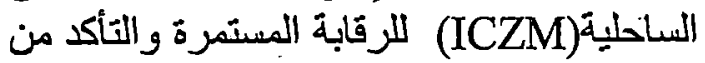

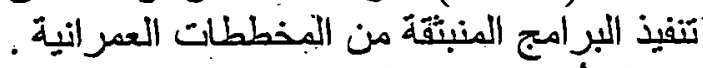

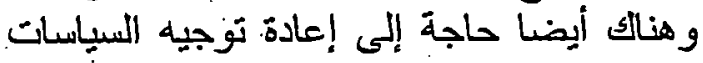

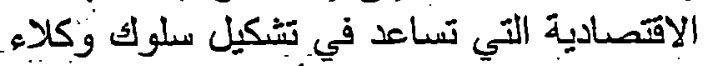

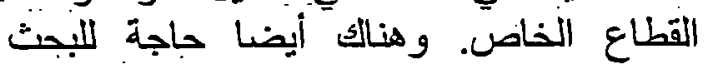

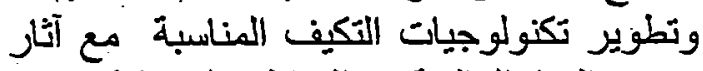
تسرب المياه المالحة في المناطق الساحلية.

ويمكن إنشاء الأحزمة الخضراء خول المناطقة

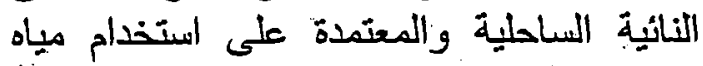
الصرف الصحي المعالجة من منتجعات سياحية الهية

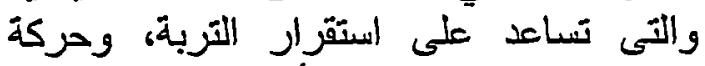

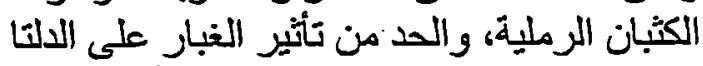

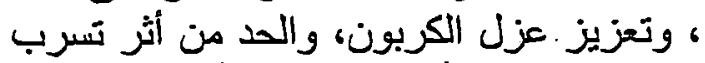

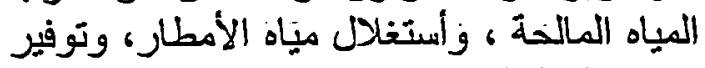
فرص العمل للسكان المحليين.

كنا أن هناك عدة خبارات أخرى والتى لاتيد من

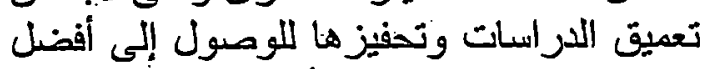
الحلول العلمية وذات تكلفة أقتصادية.

\section{V - مخاطر أنتمية العمرانية الساحلية

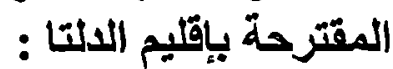

أقترحت .الهيئة العامة للتخطيط الأقليمى

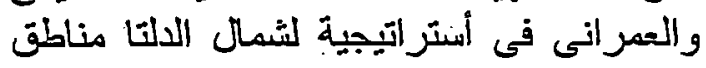

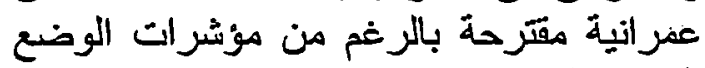

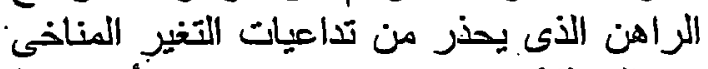

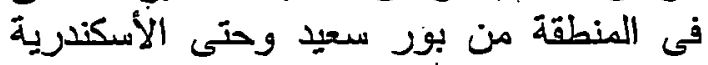

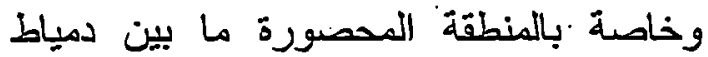
ورشيذ وأيضا منطقة أمتداد المنطقة الصناعية بلهية بمطوبس ، ومن هذه المناطق المقترحة أمتداد
المنشآت من مبان وطرق ، حيث يبذو تأثير ها

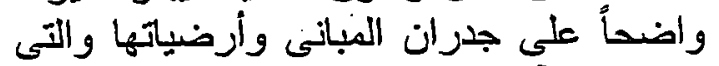

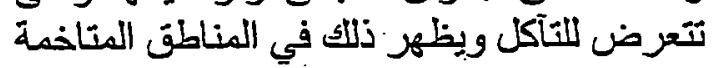

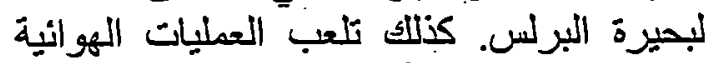
دورها السلبى في التأثير على العمران من خلانل

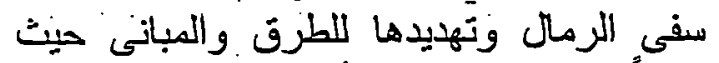

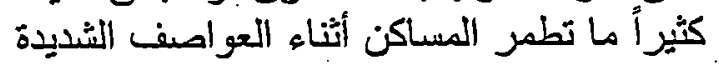

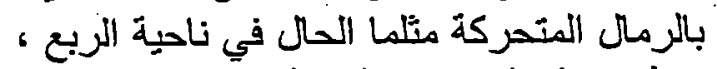

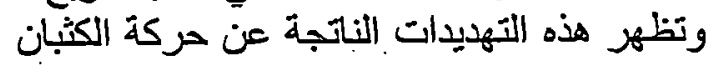

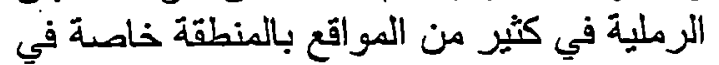

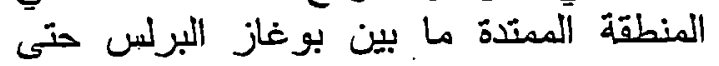
جمصة .

\section{4 ـ ـ خيارات التكيف بالتخطيط للمناطق النساحية بإقليم الدلتا : بالخطية}

ويرى العديد من العلماء أن هناك العديد من

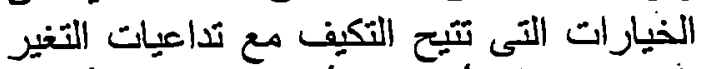

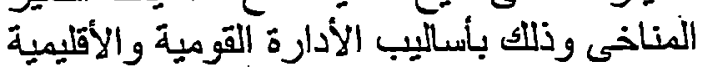

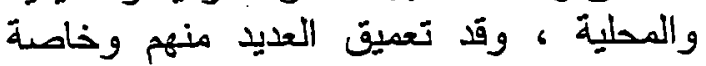

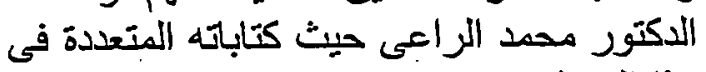

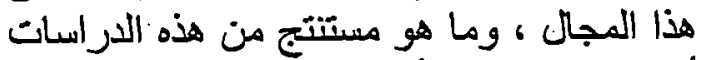

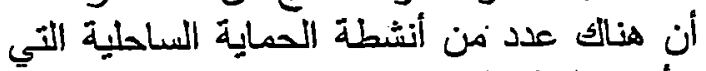

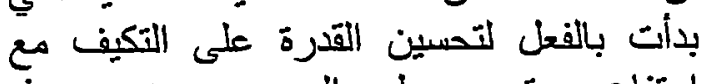

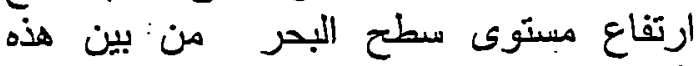

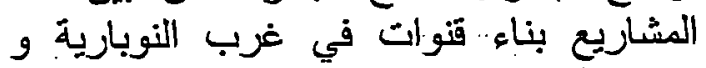

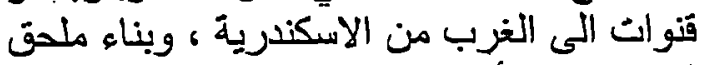

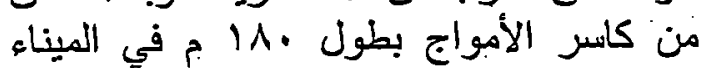

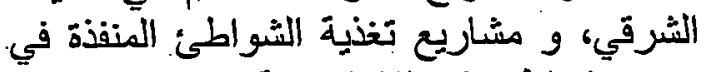

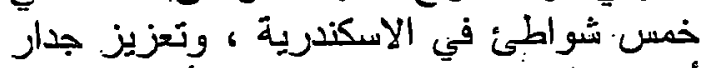

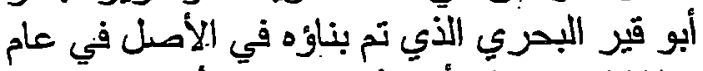
هي.

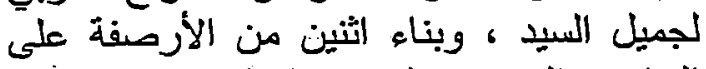

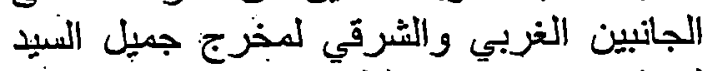

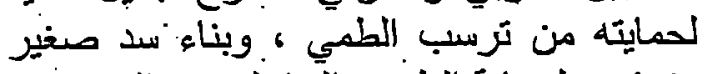

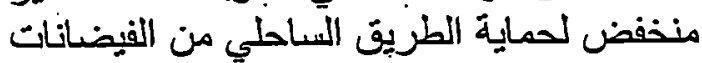
و المؤدى الى المطلار.

ويتطلب التكيف تنفيذ وتعديل القوانين القائمة التي تحد من الضعف الساحلي وصيباغة ونيلة جديدة

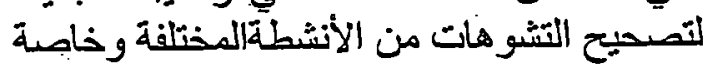

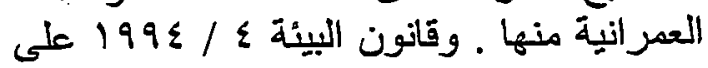


Kaooud, Moustafa Mounir Mahmoud and Shereen El-Shahaat Okeel

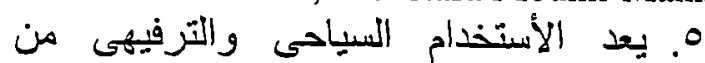

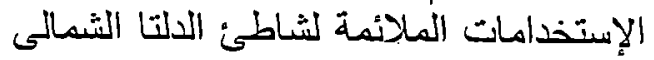

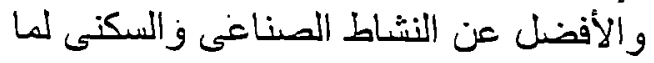

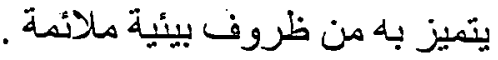

\section{1 التوصيات :}

ا ـ سن سياسبة تنظيم عالية المسنوى للتخفيف

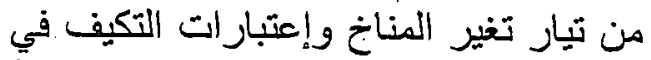
جميع القرار ات المتعلقة بالتخطيط الساحلية

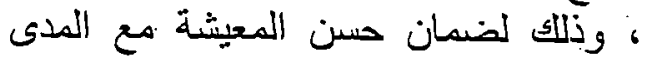

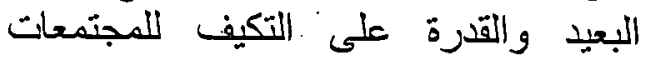

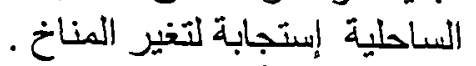

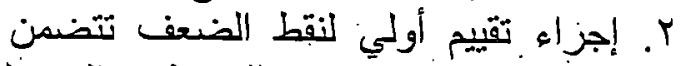

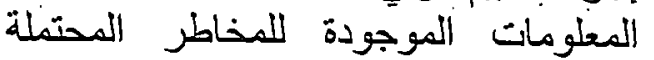

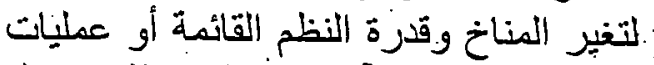

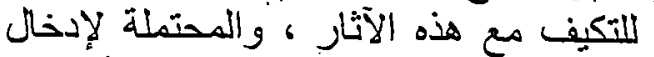

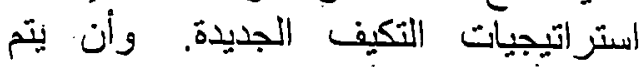

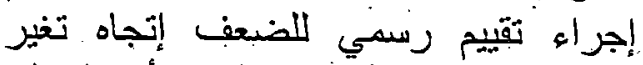
المناخ على المسثوى. الإقليمي أو إلمدلي إنيفي

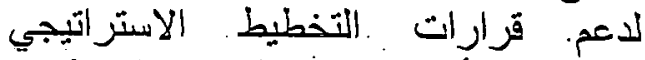
لإستخدام الأراضي ومهمة تقيبم التنمية في الاضية

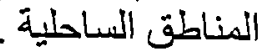
r. رفع كفائة الأنشطة الزبة إعية فيها بشكل كبيز

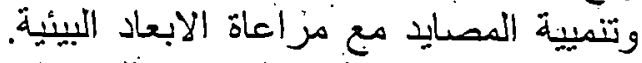

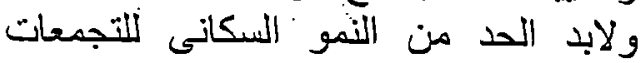

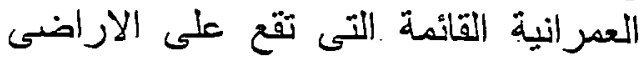
الزراعية مقابل تركيز اللمو السكاني فئي التئي

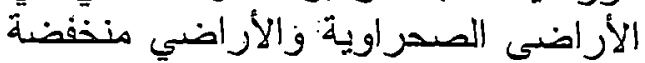
الإنتاجية وخلق مراكز وأقطاب الإني حضرية

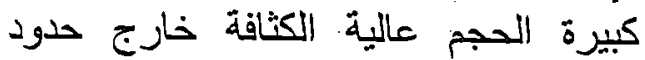

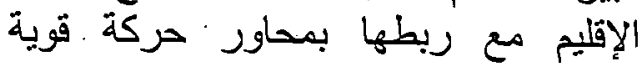
(الطرق الساحلية).

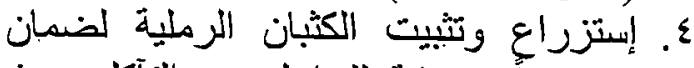

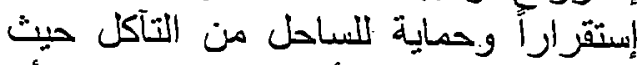

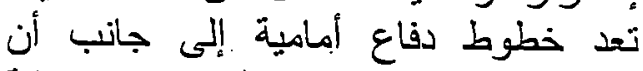

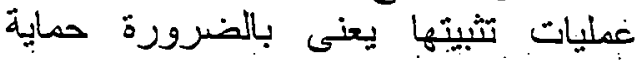

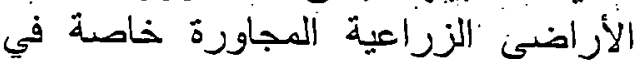

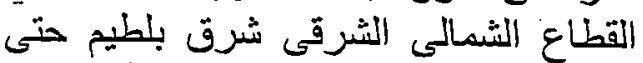

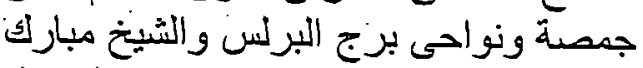

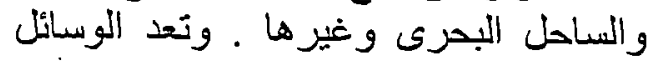

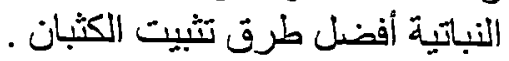

مدينة رأس البر ، والموقع الخدمى للمنطقة

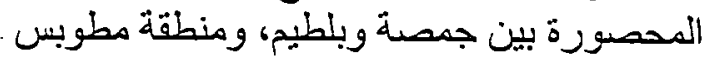

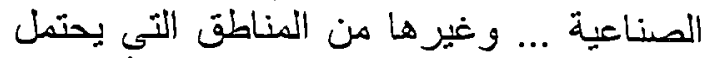

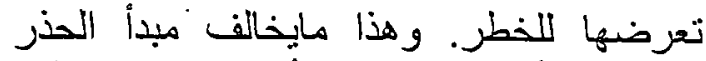

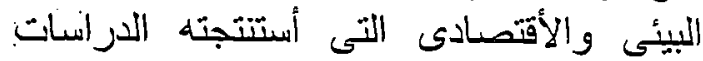
الأولية للنو احى البيئية فى المخطط.

\section{1 - نتائج البصث :}

1. التعامل مع أقليم الدلتا كمنطقة تنمويه

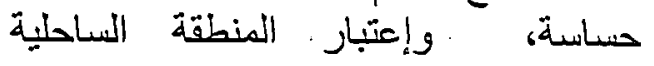

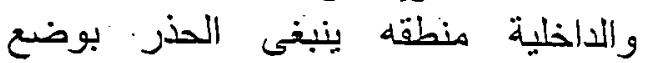

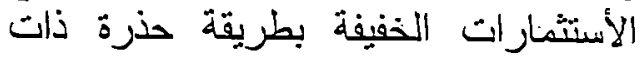

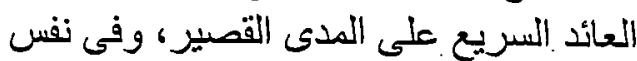

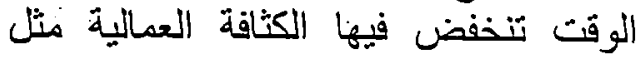

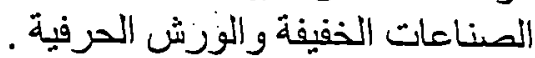

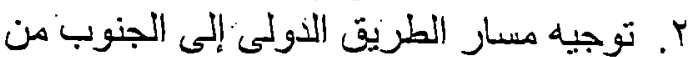

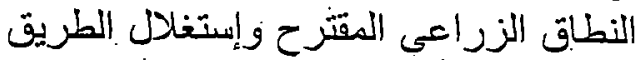
الساحلى لخدمة النطاق النياحئ النئ مع توفيز

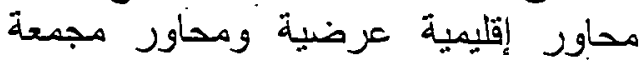
طولية وعرضية.

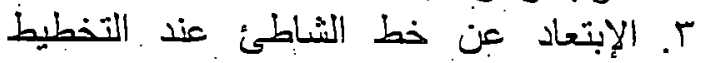

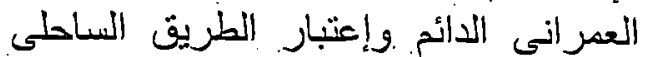

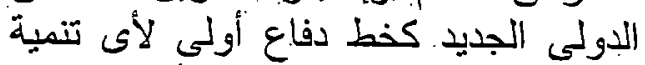

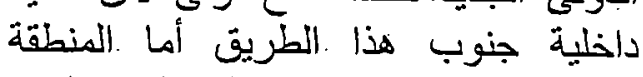

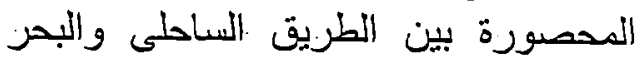
فيمكن إبتخلالها لمشرو عات تنموية بمنشآت خفيفة لا تمثل عبئًاً إقتصادياً كبيراً

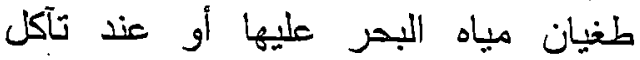

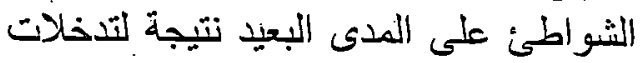

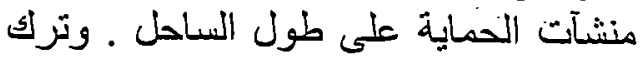

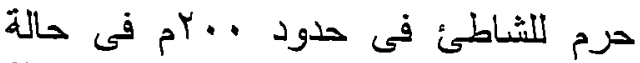

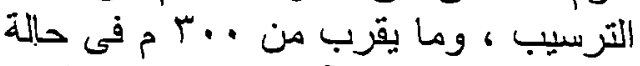

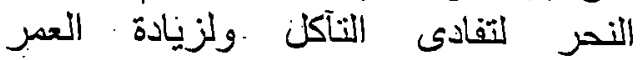

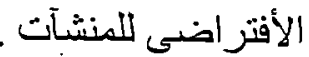

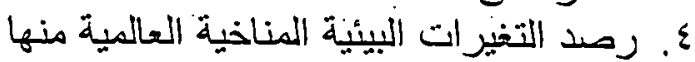

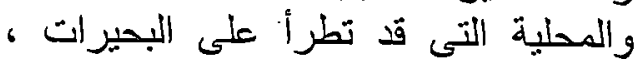

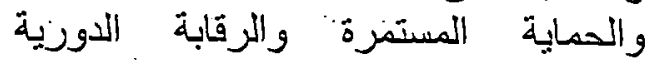
لثواطئها من خطورة التداعيات وخاصة ولية إرتفاع منسوب مياه البحر وحركة الكثبان

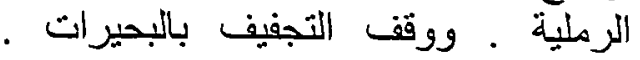
وتتجيع الصيد المنظم داخل البحيرات . 
Bolin, Bert: A History Of The Science And Politics Of Climate Change, The Role.. of the Intergovernmental Panel on Climate Change, Cambridge University Press, Cambridge, UK, 2007.

Broadus, J., Milliman, J., Edwards, S., Aubrey, D. and Gable, F. (1989), Rising sea level and damming of rivers possible effects in Egypt and Bangladesh In: Effect of changes of Stratospheric Ozone and Global Climate, ed. J. Titus, EPA.

Bruce, J., M. Egener and D. Noble. 2005. Municipal risk management for climate change. Presentation to the Climate Change Impacts and Adaptation National Conference, Montreal, Quebec, May 4-6, 2005.

Carter, TR., Parry, M.L., Harasawa, H., Nishioka, S. (1994), IPCC technical guidelines for assessing climate change impacts and adaptation. WGII of IPCC. WMO/UNEP, Geneva.

Connell, R. 2005b. Presentation to Workshop 1: Developing a climate adaptation strategy for the City of London. London. July 10, 2005.

A Comparative Analysis, World Bank Policy Research Working Paper 4136, February 2007.

Dasgupta, S., B. Laplante, S Murray, and D. Wheeler (2009) Sea-Level Rise and Storm Surges.

Delta coast", Journal of Coastal Research 11 ( Journal of Coastal Research) 11, no. 821-833.

Development Report 2003. World Bank.
○. وضع خطة منوازية لتنمية. منطقة أو مناطق

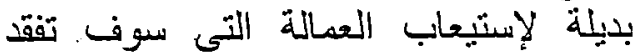

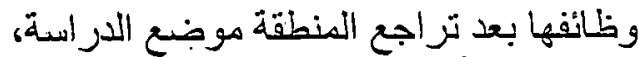
وبحبث بيدأ الإستثمار فيها فئى الخمس لإنى

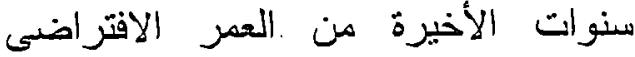

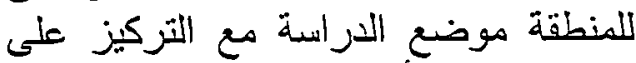

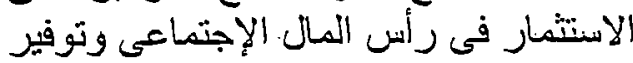

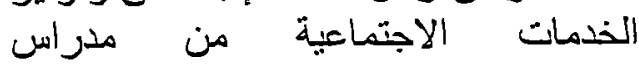
ومستشفبات وغيرها. ومن ثم الإنتقال من الني المنطقة موضع الدرابة الى المناطق البديلة

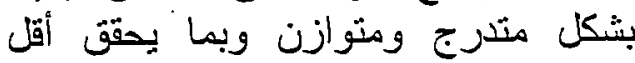
خسارة ممكنة.

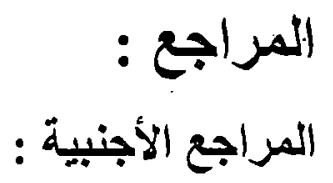

Abu-Zeid, M. and Abdel-Dayem, S. (1992), Egypt Programmes and Policy Options for Facing the Low Nile Flows, Oxford.

Allaby, Michael: Atmosphere, A Scientific History of Air, Weather, and Climate, Facts On File, Inc., Infobase Publishing, New York, 2009.

Assessment Report of the IPCC. Cambridge University Press, Cambridge, UK.

Barry, R. and Chorley R.: Atmosphere, Weather and Climate, Eighth Edition, Routledge , London, 2003.

Bigio, A.G. 2002. Cities and Climate Change. A discussion paper for the World.

Tabo and R.; Yanda, P. (2007) "Climate Change 2007: Impacts, Adaptation and Vulnerability: Cambridge University Press. 
Kaooud, Moustafa Mounir Mahmoud and Shereen El-Shahaat Okeel

Alexandria Governorate; Egypt. Journal of Coastal Research, Special Issue No. 14,

Hicks, R.,(2005) Senior Engineer, Regional Utility Planning, Policy and Planning.

Howell, D., Special Projects Manager, Air Quality and Climate Initiative, Department of Natural Resources and ${ }^{-}$Parks, King County, Washington. 2006. Interviewed by authors, Seattle, Washington. April 26.

IPCC, 2007, Climate Change 2007. Contribution of Working Group I to the Fourth Assessment Report of the Intergovernmental Panel on Climate Change, edited by Solomon, S., D. Qin, M. Manning, Z. Chen, M. Marquis, K.B. Averyt, M. Tignor, and H.L. Miller, Cambridge University Press, Cambridge, UK and New York, NY.

Jobbins, Guy (2008) Adaptation to the Impacts of Sea Level Rise in the Nile Delta Coastal Zone.

Leary, N., Adejuwon J., and Barros V. (2008) Climate Change and Adaptation, London.

Leary, N., and Kulkarni J. (2007) Climate Change Vulnerability and Adaptation in Developing Country Regions, Draft Final Report of the AIACC Project, Washington: The International START Secretariat.

McBean, G. and D. Henstra. 2003. Climate Change, Natural Hazards and Cities. ICLR Research Paper Series - No. 31, Institute for Catastrophic Loss Reduction, Toronto.
EEAA (1995,1999), Framework of National Action Plan for Dealing with Climate Change. U.S. Country. El Raey M., Frihy, O.; Nasr S.M; Dewidar Kh (1998), Vulnerability assessment of sea level rise over Port- Said Governorate, Egypt. Environ. Monit. Assess 56: 113-128 El Raey Mohamed;Dia El Quosy; Mahmoud El Shaer; Osama El Kholy and Ayat Soliman; Egypt: Inventory and Mitigation options and vulnerability and adaptation Assessment; Position paper; COP6, Berlin,1996.

El Raey, M. (19.97), Vulnerability. assessment of the coastal zone of the Nile delta of Egypt to the impacts of sea level rise. In: Ocean and Coastal Management 37: 29-40.

El Raey, M. (1997), Vulnerability of the Nile Delta Coastal Zone of Egypt to the Impact of Sea-Level Rise.

El Raey, M. Y. Fouda and S. Nasr (1997), GIS assessment of the vulnerability of Rosetta area, Egypt. In: Impacts of Sea Rise; Environ Monit. Assess 47: 59-77.

El Raey, M., Kh. Dewidar, and M. El Hattab (1999), Adaptation to the impacts of sea level rise in Egypt.

El Raey, M., O. Frihy, S.M. Nasr, S. El-Kaffas, S. Ahmed, Y. Fouda, G.M. El-Hattab, and G. Kh. Dewidar (Undated), Vulnerability of the Coastal Zone of Egypt to Sea Level Rise. PDF file. U.S. Country Studies Program;. Washington, DC. El Raey, M., S. Nasr, O. Frithy, S. Desouki, and K. Dewidar, K. (1995), Potential impacts of accelerated sea-level rise on 


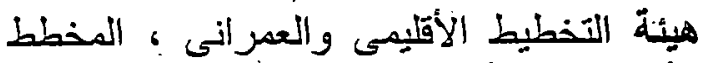
الأستراتيجى لأقليم الالنتاوشمال الدلنتا.
McGuire Elsner, J. Littell, and L Whitely Binder (eds). Center for Science in the Earth System, Joint Institute for the Study of the Atmosphere and Oceans, University of Washington, Seattle, WA.

McKinney, Vanessa: Sea Level Rise and the Future of the Netherlands, Inventory of Conflict and Environment, ICE Case Studies, 212. May, 2007.

NEAA, Netherlands Environmental Assessment Agency: Dutch dikes, and risk hikes, A thematic policy evaluation of risks of flooding in the Netherlands, Extended summary, Bilthoven, 2004.

Needs; (submitted, 2003).

Roaf, S, Crichton D., and Nicol F. (2005) Adapting Buildings and Cities for Climate Change.

Rosenzweig, C., W.D. Solecki, and R. Slosberg. 2006. Mitigating New York City's Heat Island with Urban Forestry, Living Roofs, and Light Surfaces. A report to the New York State Energy Research and Development Authority.

\section{المراجع المربية :}

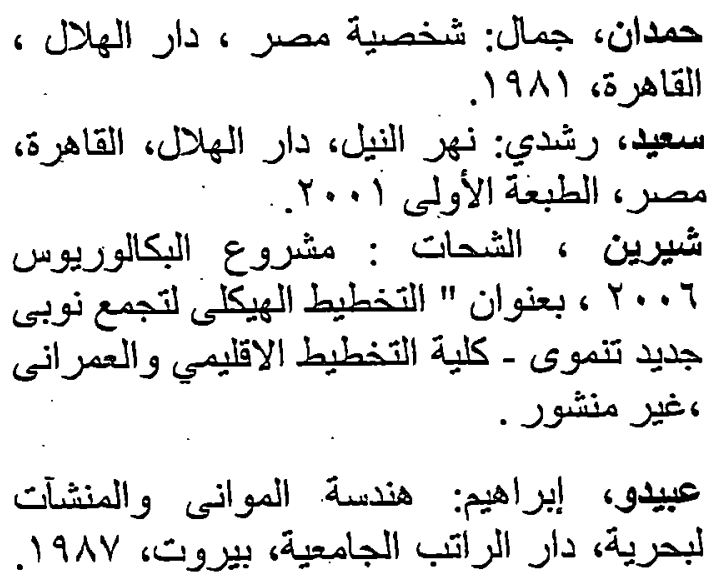

